\title{
WestVirginiaUniversity
}

THE RESEARCH REPOSITORY @ WVU

Graduate Theses, Dissertations, and Problem Reports

2010

\section{Learned resourcefulness in working women who are poor and uninsured}

Denise DeMaria Lucas

West Virginia University

Follow this and additional works at: https://researchrepository.wvu.edu/etd

\section{Recommended Citation}

Lucas, Denise DeMaria, "Learned resourcefulness in working women who are poor and uninsured" (2010). Graduate Theses, Dissertations, and Problem Reports. 3088.

https://researchrepository.wvu.edu/etd/3088

This Dissertation is protected by copyright and/or related rights. It has been brought to you by the The Research Repository @ WVU with permission from the rights-holder(s). You are free to use this Dissertation in any way that is permitted by the copyright and related rights legislation that applies to your use. For other uses you must obtain permission from the rights-holder(s) directly, unless additional rights are indicated by a Creative Commons license in the record and/ or on the work itself. This Dissertation has been accepted for inclusion in WVU Graduate Theses, Dissertations, and Problem Reports collection by an authorized administrator of The Research Repository @ WVU.

For more information, please contact researchrepository@mail.wvu.edu. 
Learned Resourcefulness in Working Women who are Poor and Uninsured

\author{
Denise DeMaria Lucas
}

Dissertation submitted to the School of Nursing at West Virginia University in partial fulfillment of the requirements for the degree of

Doctor of Philosophy in Nursing

\author{
Mary Jane Smith, PhD, RN, Chair \\ Roger Carpenter, PhD, RN \\ Stacey Culp, PhD \\ Alvita Nathaniel, PhD, FNP-BC, FAANP \\ Irene Tessaro, $\mathrm{DrPH}, \mathrm{RN}$
}

School of Nursing

Morgantown, WV

2010

Key Words: Learned Resourcefulness, Uninsured, Working Poor, Well Being 


\section{ABSTRACT \\ Learned Resourcefulness in Working Women Who are Poor and Uninsured \\ Denise DeMaria Lucas}

Statement of Problem: Women with limited resources lack basic health coverage. More women than men are poor. The majority of working women remain in low wage, insecure jobs with little prestige and stability, and no benefits. Low wage earners are at the greatest risk for being uninsured. Being the working poor and without medical insurance is a barrier to health care. The purpose of this descriptive, correlational study was to describe the interrelationships between learned resourcefulness (LR), health status, and well-being (WB) in working women who are poor and uninsured.

Procedure: A convenience sample of 132 working women who were at least $100 \%$ below poverty level, uninsured, and between the ages of 25 and 64 were participants in a study at a free clinic between the weeks of July 27 and August 17,2009 . Participants completed a demographic questionnaire, a survey measuring health status with health indicators from the WV Behavioral Risk Factor Surveillance Survey, the Index of Well-Being measuring WB, and the SelfControl Schedule measuring LR.

Results: The sample mean age was 45.11 years with a range between 25 and 65 years. Subjects in this study scored lower on health status indicators than the comparison population from the State of West Virginia. The sample mean of LR of 19.5 compared to the median of 22 indicated the data were skewed to the left. There was a statistically significant $(p=.001)$ positive relationship between learned resourcefulness and well-being. As WB increased LR increased. Learned resourcefulness, education, and the number of persons living in the home together predicted $28 \%$ of the variance in WB $\left(R^{2}=.276, p=.017\right)$.

Conclusions: Implications for nursing research were identified and include the need for replication of the study in another sample in a different region to validate current findings. A qualitative study addressing questions on individual tendencies with directed content analysis should be attempted. Concerning practice, the findings encourage advanced practice nurses to consider caring for groups of patients and to teach skills promoting resourcefulness. The social history commonly gathered should change to inquire about aspects of WB that may be impinging $L R$. 


\section{TABLE OF CONTENTS}

Abstract.........................

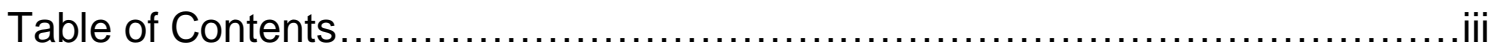

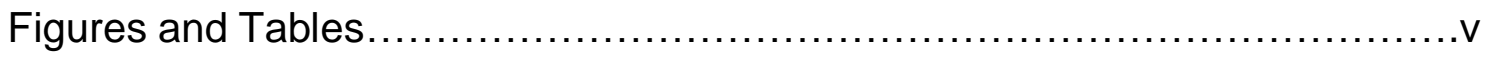

Chapter 1: Introduction of the Problem......................................

Theoretical Perspective ............................................... 5

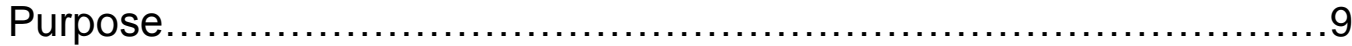

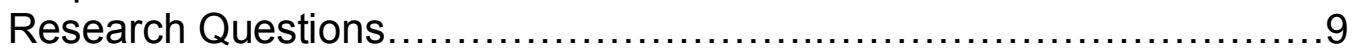

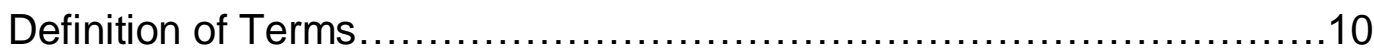

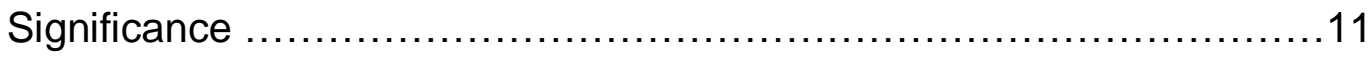

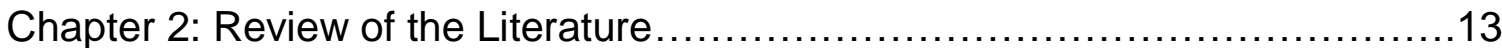

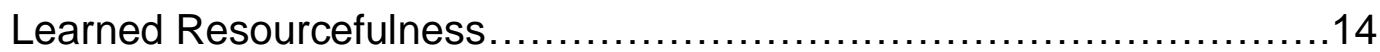

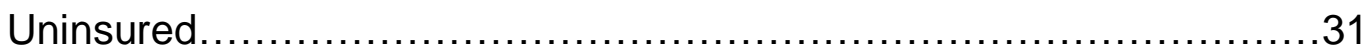

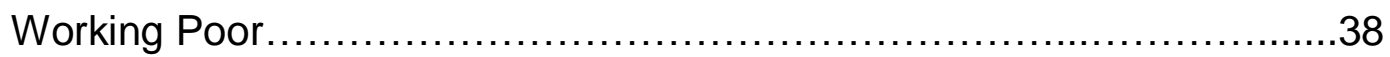

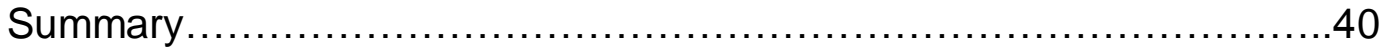

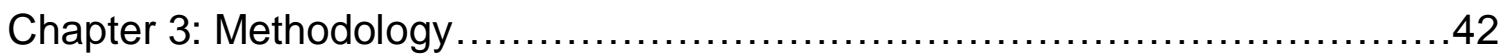

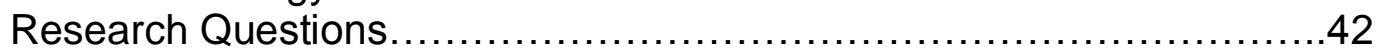

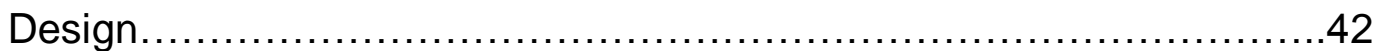

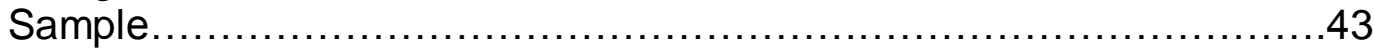

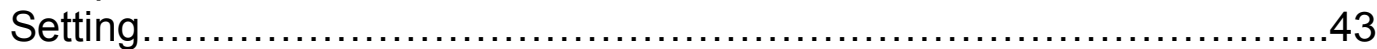

Measurement of Concepts............................................ 44

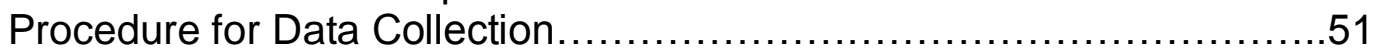

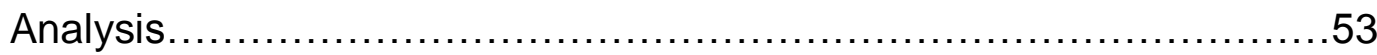

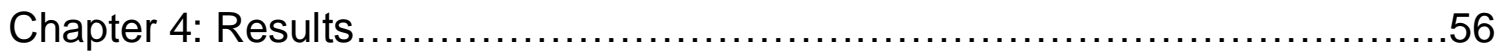

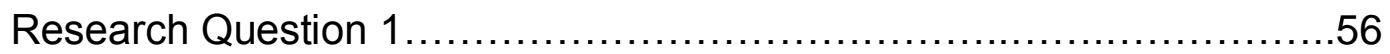

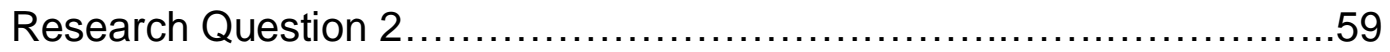

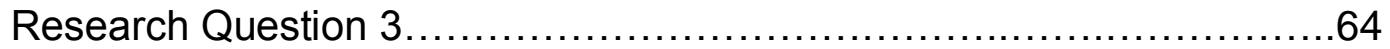

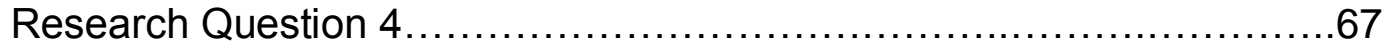

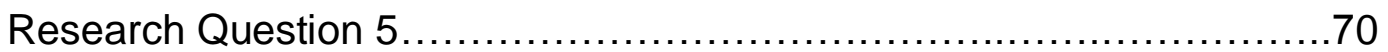

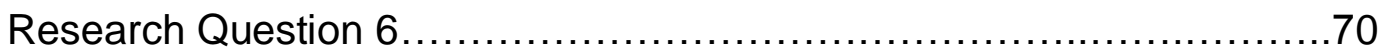

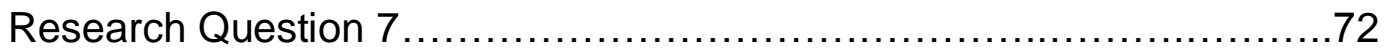

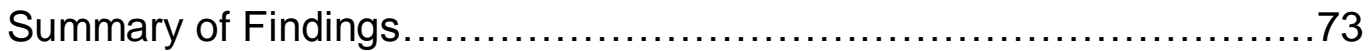

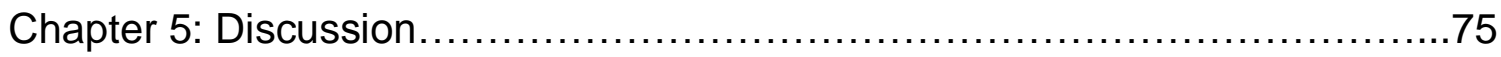

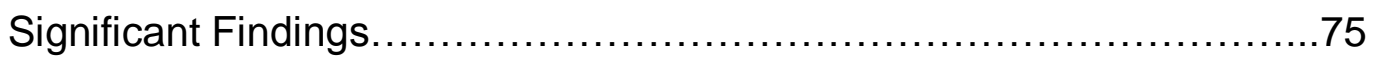

Study Strengths and Limitations $\ldots \ldots \ldots \ldots \ldots \ldots \ldots \ldots \ldots \ldots \ldots \ldots \ldots \ldots \ldots 2$

Implications for Nursing Research..................................... 83

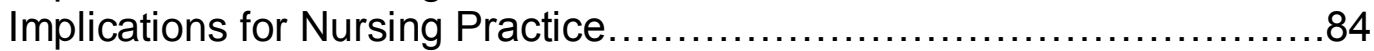




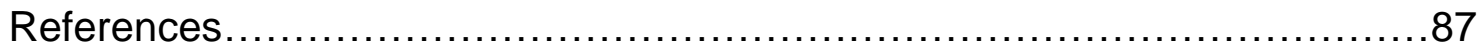

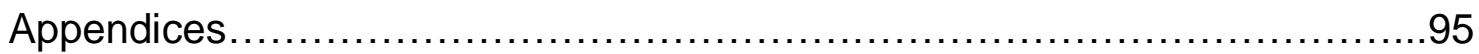

Appendix A: Self Control Schedule....................................96

Appendix B: Index of Well-Being ......................................100

Appendix C: Behavioral Risk Factor Survey Items......................101

Appendix D: Demographic Questionnaire..............................102

Appendix E: Wheeling Health Right Permission Letter....................104

Appendix F: Participant Recruitment Flyer............................105

Appendix G: Participant Participation Letter...........................106 


\section{FIGURES}

Figure $1 \quad$ Model of Learned Resourcefulness...............................6

Figure 2 Histogram Representing Learned Resourcefulness Scores........65

\section{TABLES}

Table 1 Distribution Over Time of Articles Measuring Learned Resourcefulness...................................................14

Table 2 Description of Demographic Information.........................58

Table $3 \quad$ Overview of Health Indicators.....................................61

Table $4 \quad$ Relationship of Health Status Indicators and Demographics.......62

Table $5 \quad t$-tests for Number Living in Home and for Age by Health Indicator...........................................................63

Table 6 Significant $t$-tests for Number Living in the Home and for Age by Health Indicator....................................................64

Table 7 Analysis of Variance of Learned Resourcefulness and Demographic Variables..........................................66

Table 8 Analysis of Variance of Well-Being and Demographic Variables...68

Table $9 \quad t$-tests for Well-Being by Health Indicators............................69

Table 10 Prediction of Well Being with Learned resourcefulness and Significant Demographic Variables..................................72

Table 11 Prediction of General Perception of Health with Learned Resourcefulness and Significant Demographic Variables............73 
Chapter 1: Introduction of the Problem

This study addressed the learned resourcefulness (LR) of working women who are poor, uninsured, and have limited health resources available to them. The interest in LR in this group stemmed from the author's clinical observations and experiences with working women who are poor and uninsured. These observations have shown ways in which the women have learned to be resourceful and include dealing with health issues, scarce resources, and solving daily problems. Women with limited resources lack basic health coverage, particularly non-pregnant, low-income women who do not meet Medicaid eligibility requirements (Johnson, 2006) and are less likely to have a consistent health care provider or usual medical home for care (Hoffman, 2007). When surveyed, less than $25 \%$ of uninsured individuals knew of a place in their community that offered affordable or free care (Hoffman, 2007).

When describing working women who face poverty, it is critical to understand recent poverty statistics, trends in the statistics, and the way statistics are determined. Two primary federal groups collect and report poverty information: the U.S. Census Bureau and the U.S. Department of Health and Human Services. The official poverty rate in 2006 was $12.3 \%$ or 36.5 million people (U.S. Census, 2006) and increased to $13.2 \%$ or 39.8 million in 2008 (U.S. Census, 2009). In 2006, the percentage of all families below poverty level was 9.8 (U.S. Department of Health and Human Services, 2008), increasing to 10.3 percent in 2008 (U.S. Census, 2009). The percentage of female heads of 
households below poverty level was 28.3 (U.S. Department of Health and Human Services, 2008), increasing slightly to 28.7 percent in 2008 (U.S. Census, 2009). There are two slightly different measures of poverty: poverty thresholds and poverty guidelines (U.S. Department of Health and Human Services, 2008). The poverty threshold is the original version of the federal poverty measure. The thresholds are updated each year by the Census Bureau and are used for statistical purposes. Official poverty calculations are figured by thresholds. Poverty guidelines are issued each year in the Federal Register by the Department of Health and Human Services and are a simplification of the poverty thresholds for administrative purposes, such as determining financial eligibility for federal programs (U.S. Department of Health and Human Services, 2008).

Researchers, such as Shipler (2005), do not define poverty as a category delineated by monetary income. Rather, Shipler (2005) notes poverty is an unmarked area along a continuum, representing an area of hardship that society may not recognize. More people officially labeled as "poor" are weighted down with the troubles associated with poverty.

More women than men are poor. For single women, the poverty gap is larger with $24.1 \%$ for women compared to $17.9 \%$ for men (Spriggs, 2007). Spriggs (2007) identifies two reasons why some people are not able to rise above poverty, noting either they do not work or do not earn enough money. Women serving as heads of household have added responsibilities of supporting and raising dependent children, the burden of household labor, and often the obligation of caring for elderly parents (Luce \& Brenner, 2006; Spriggs, 2007). 
The majority of working women remain in low wage, insecure jobs with little prestige and stability, and no benefits (Luce \& Brenner, 2006). Dodson (2007) contends much of the employment available to women is not enough to support a family or provide a way out of poverty. As of 2005 the median hourly wage for all women workers was $\$ 12.50$ and $\$ 15.57$ for men. In 2009 the median earnings for both men and women declined. For women the decline was 1.9\% (U.S. Census, 2009). The average wages in female-dominated occupations have remained consistently low and contribute to keeping working women in poverty (Luce \& Brenner, 2006).

Being poor often leads to being uninsured. People with low incomes are at the greatest risk for being uninsured (Hoffman, 2007). More uninsured individuals exist today than in prior years and the numbers continue to grow steadily (Kaiser Family Foundation, 2006). In 2006, 36.5 million people were in poverty, with both the percentage and number of people without health insurance increasing (U.S. Census, 2006). National surveys estimate the number of uninsured individuals ranged from 20 to 80 million persons with a "point in time" range of non-elderly uninsured persons from 41 to 46 million (Kaiser Family Foundation, 2006). The rates of uninsured men have increased modestly from $21.9 \%$ in 2003 to $22.5 \%$ in 2006 (Economic Research Initiative, n.d.). The rates of uninsured women have increased from 18.5\% in 2003 to 18.8\% in 2006 (Economic Research Initiative, n.d.), and the number of uninsured women is expected to exceed men in the next few years (Kaiser Family Foundation, 2006). 
A reduction in Medicaid services, in addition to a decline in employer sponsored health plans, has resulted in a significant number of low income women without health insurance. Women experience a lack of insurance in ways that are different from men. Women frequently find themselves as working mothers who are single or divorced, caring for children, and other family members (Galambos, 2006; Johnson, 2006). Generally, working, uninsured women often find themselves single and head of household, face added financial strains, life pressures, and family responsibilities while laboring the best they can to get by (Luce \& Brenner, 2006). The experience of being the "working poor" and often without medical insurance is a formidable barrier to health care for many Americans.

Studies consistently indicate low-income women have poorer overall health (Galambos, 2006; Hoffman, 2007). Galambos (2006) contends poor women are three times more likely than non-poor women to report fair or poor health and to report the presence of two or more health conditions. Compared to insured women, uninsured women often face barriers to health care and are less likely to receive primary care services with the same frequency as those who are less poor or insured (Orne, Fishman, Manka, \& Pagnozzi, 2000). Uninsured women are known to use health services less frequently, opting to postpone medical procedures. When poor women present for medical care, problems are often more severe and the emergency department frequently is the source of care. Preventative health measures such as immunizations, family planning, 
prenatal care, breast exams, and mammography are also obtained less frequently (Orne, Fishman, Manka, \& Pagnozzi, 2000).

Theoretical Perspective

Learned resourcefulness (LR), as described by Rosenbaum (1990), served as the theoretical foundation for this study. Rosenbaum (1990) described LR as "an acquired repertoire of behavioral and cognitive skills with which the person is able to regulate internal events such as emotions and cognitions that might otherwise interfere with the smooth execution of a target behavior" (p. xiv). Stated more succinctly, Rosenbaum (1990) described LR as "What people do when stressful circumstances call for self-direction with a set of well-learned behaviors and skills by which a person self-controls their behavior" (p. 4).

Rosenbaum's early interests in psychological concepts such as stress and coping began in the 1970 s with graduate students. Much of the research Rosenbaum supervised with students examined the role that cognitive and affective factors play in behavior therapy. The research evolved, leading to the recognition of resourcefulness in handling stressors. Rosenbaum (1990) states ..."modern society is dynamic and most individuals are constantly faced with highly demanding and ever-changing behavioral repertoires. These challenges produce intense physiologic and emotional reactions that often have adverse effects on well-being. Most people do not succumb completely to situational pulls and know how to manage behavior so it promotes health rather than illness" (p.3). Rosenbaum's work throughout the 1980's and 1990's can be found in two books and multiple journal articles. 
LR is a process that involves individual tendencies, which lead to health consequences (Rosenbaum, 1990). Situational factors trigger emotional and physiologic reactions that affect health. The individual tendencies of cognitive strategies, problem solving skills, the ability to delay immediate gratification, and the belief in one's ability to perform affect health status and well being. Figure 1 is a model of LR created to guide the study. The figure shows the interaction between individual tendencies and consequences.

Figure 1: Theoretical Model of Learned Resourcefulness

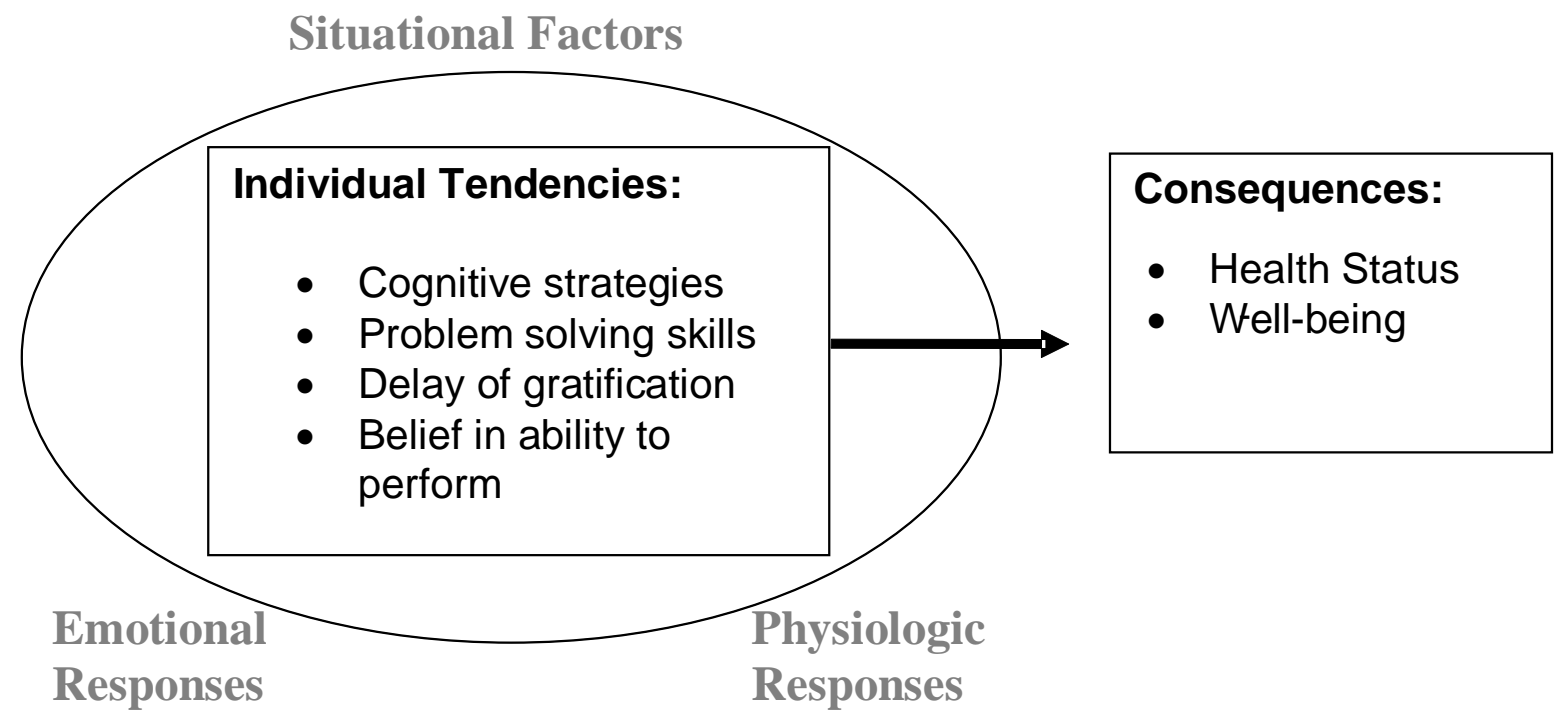

Emotional responses occur with every day unique life pressures and demands faced by individuals that impact their feeling state. If there are too many pressures and demands at one time, the individual may not adequately attend to these pressures and demands, and coping may be reduced. Too many pressures and demands at once may interfere with the four individual tendencies of cognitive strategies, problem solving skills, the ability to delay immediate 
gratification, and the belief in the ability to perform (Rosenbaum, 1990). In contrast, persons who have learned to be resourceful take actions in recognition of life pressures and demands to maintain a level of health and well-being and may adopt practices promoting health.

Physiologic responses occur with circumstances related to a general state of health and well-being. The manner in which a threat is perceived (real or imagined) will manifest in a physiologic response related to the general state of health and well-being. When recognition of calming self-statements verify the threat as more perceived than real, there tends to be a reduction in the perception of the threat through positive feedback. The positive feedback leads to a higher level of resourcefulness. The higher level of resourcefulness is demonstrated by the individual taking actions to promote health and well-being (Rosenbaum, 1990).

Individual Tendencies

The four individual tendencies of LR include the use of cognitive strategies, problem solving skills, the ability to delay immediate gratification, and the belief in the ability to perform. Cognitive strategies are defined as an individual's ability to recognize real or imagined change. The perception and interpretation of change occurs automatically without conscious effort (Rosenbaum, 1990, p.5). Problem solving skills are defined by Rosenbaum (1990) as "...constellations of complex skills which are evoked by many situations but also have the quality of providing the basis for additional learning" (p. 9). Problem solving is not a personality trait, but a set of learned behaviors in 
constant interaction with the social and physical environment of the individual.

Delay of immediate gratification is accomplished when an individual engages in anticipatory self-regulation. Anticipatory self-regulation is initiated when certain information is recalled that disrupts the progress of a planned or habitual behavior (Rosenbaum, 1988). Belief in the ability to perform is defined as confidence to execute necessary behaviors or control various emotions. The ability to perform is fostered by the successful practice and use of cognitive strategies, problem solving skills, and successful delay of gratification (Rosenbaum, 1990). In this study individual tendencies were assessed using the Self Control Schedule (SCS) developed by Rosenbaum (1990).

\section{Consequences}

This study included an examination of the consequences that are important gauges of health and well-being in uninsured, working women. Consequences are a reflection of the ability to employ the four individual tendencies (Rosenbaum, 1990). Consequences are produced by a cause or necessity following from a set of conditions. Consequences chosen for this study were health status and the general state of well-being (WB).

The consequences of health status were furthered measured in terms of specific health indicators. Health indicators were used to identify the working, uninsured woman's ability to adopt health-promoting behaviors. Health indicators include distinct responses to medical care and health. Examples of specific health indicators for this study include identifying whether the woman has a health care provider, a chronic medical condition such as hypertension or 
diabetes, smokes, has had a Papanicolaou (PAP) test in the past three years, has needed medical care in the last year but could not afford it, a general health rating, and a life-satisfaction rating (WV Behavioral Risk Factor Survey Report, 2007, 2009).

WB is a reflection of the level of satisfaction a person gathers and assimilates from critical domains of life. Critical domains are those areas which have significance for all or most people, and contribute in some degree to the general quality of life experience (p.14). WB includes the basic essentials of life such as food, housing, and material goods along with less tangible values such as a sense of achievement and identification with the community and was defined as the level of satisfaction with the overall quality of life (Campbell, Converse, \& Rodgers, 1976).

\section{Purpose of the Study}

The purpose of the study was to describe the interrelationships between $\mathrm{LR}$, health status, and WB in working women who are poor and uninsured.

\section{Research Questions}

The research questions to be addressed were:

1. What are the demographics of working women who are poor and uninsured?

2. How is health status described in working women who are poor and uninsured?

3. How is LR described in working women who are poor and uninsured?

4. How is well-being described in working women who are poor and uninsured? 
5. What is the relationship between LR and well-being?

6. How do LR and significant demographic variables work together to predict well-being?

7. How do LR and significant demographic variables work together to predict perception of general health?

\section{Definition of Terms}

\section{Theoretical Definitions}

Learned resourcefulness is an acquired repertoire of behavioral and cognitive skills with which a person is able to regulate internal events such as emotions and cognitions that might otherwise interfere with the smooth execution of target behaviors (Rosenbaum, 1990).

Consequences are a reflection of the response to the ability to employ the four individual tendencies (Rosenbaum, 1990).

Working poor are persons who have the experience of multiple, interlocked factors contributing to poverty to include financial, psychological, personal, and social aspects (Shipler, 2005).

\section{Operational Definitions}

Learned resourcefulness is an assessment of the four individual tendencies and is measured by the Self Control Schedule (Rosenbaum, 1990).

Consequences include health status and well-being. Health status is assessed by responses to health indicators from the WV Behavioral Risk Factor Survey Report $(2007,2009)$.Well-being is the level of satisfaction with the overall 
quality of life, measured by the Index of Well Being (Campbell, Converse, \& Rodgers, 1976).

Working poor are individuals meeting the federal definition of poverty while holding paying jobs and attending a free health care clinic.

Uninsured are those who have no current health insurance.

Significance

This study is grounded in the perspective of nursing through a focus of human health phenomena. Human health phenomena include the concepts of LR and WB. An assumption underpinning the study is that persons who are resourceful engage in health promoting behaviors that lead to improved WB. Thus, the findings from the study offer a contribution to the knowledge base of nursing.

There is a gap in the literature concerning LR in working women who are poor and uninsured. To date no evidence could be found relating LR to women, those who are poor, or those who are uninsured. This study began to lay the foundation by studying LR and the consequences of health and WB. Findings from this study are significant as an area of inquiry since the number of poor, uninsured working women is projected to increase (Kaiser Family Foundation, 2006).

There are limited writings on LR in the nursing literature, thereby reducing exposure to the discipline of nursing. Zauszniewski, the primary nurse researcher examining LR, and has laid a foundation of conceptual and empirical work in specific populations for researchers to build upon, thus introducing the concept to 
nursing science. Room exists to advance the maturity of LR in the discipline of nursing by building on Zauszniewski's program of research. This study advances LR by adding the results from this study of LR in working women who are poor and uninsured. Specifically this study contributes findings on LR, health, and well-being of working women who are poor and uninsured.

Findings from this study on the relationship between LR and the consequences of health status and well-being may affect advanced practice nursing. Dissemination of the findings to nurses who care for women who are poor and uninsured in the context of this study may add to the practice repertoire the advanced practice nurse utilizes. Individuals who are working, yet poor and uninsured come to the advanced practice nurse with unique situations reflective of limitations in health and well-being. The treatment approach calls for change, impacting how the poor and uninsured are cared for. These unique situations may call for the recognition of $L R$ in an approach to care. 
Chapter 2: Review of the Literature

This chapter presents an overview of the literature on LR, the working poor, and uninsured. The search strategy for this study explored databases in the areas of gender and sexuality, health sciences, psychology, and sociology. The following databases were queried with pertinent search terms: Academic Search Complete, Alt. HealthWatch, Biological Abstracts, CINAHL, Health Source Consumer Edition, Health Source: Nursing/Academic Edition, International Pharmaceutical Abstracts, Medline, Mental Measurement Yearbook, Psych ARTICLES, PsychINFO, Social Work Abstracts, Tests in Print, and Women's Studies International. Published journal articles on LR were available from 1983 to present with 105 items currently available. Table 1 presents a breakdown of articles published between 1983 and 2008. Zauszniewski, the primary nurse researcher, has contributed 18 empirical articles to the body of nursing literature since 1994. All of Zauszniewski's articles are included in the review (18), in addition to a small sample of publications (3) from other researchers. Disciplines other than psychology and nursing have examined LR and include social work, education, and medicine. A sample of research from psychological researchers (11) is also included. 
Table 1: Distribution Over Time of Articles Measuring LR

\begin{tabular}{l|llll}
\hline Time Span & Psychology & Nursing & Zauszniewski & Other \\
\hline $1983-1987$ & 7 & 0 & 0 & 0 \\
$1988-1992$ & 9 & 0 & 0 & 4 \\
$1993-1997$ & 11 & 3 & 7 & 7 \\
$1998-2002$ & 10 & 5 & 6 & 3 \\
$2003-2007$ & 9 & 7 & 4 & 4 \\
$2008-2009$ & 4 & 4 & 1 & 0 \\
\hline Total: $\mathbf{n}=\mathbf{1 0 5}$ & 50 & 19 & 18 & 18 \\
\hline
\end{tabular}

The major categories of the review were LR, the uninsured, and the working poor. The literature on LR was organized by the topics of pressures and demands, and also by health and WB. Pressures and demands were examined in the groups of parent-child, college students, adults, and the aged. Health and WB was studied in the same groups, however no literature exists on parent-child. Literature on the uninsured was organized by the topics of WB and health. The literature on the working poor stemmed from government, business, and economic sources.

\section{Learned Resourcefulness}

Researchers in the disciplines of psychology and nursing have been the primary investigators of LR, thus adding to the current body of knowledge. The definition of LR is used consistently throughout each work and reflects Rosenbaum's (1980) original writings. LR refers to what people do when stressful circumstances call for self-direction with a set of well-learned behaviors and skills to control their behavior. Zauszniewski (1995a), a nurse researcher, defined LR 
as a personal characteristic acquired through interactions with others, demonstrated by one's abilities to independently manage daily activities. Zauszniewski (1995a) conceptualized LR as a positive health seeking behavior learned through life that helps to attain, maintain, or regain health. Rosenbaum (1990) stated the behaviors and skills of LR are learned, beginning at birth. Both of these definitions are in agreement that the behaviors and skills are learned.

The Self-Control Schedule (SCS) developed by Rosenbaum (1990) is the sole instrument available to measure LR. The dynamic phenomenon of LR is subjective, based on an individual's self-report. Rosenbaum developed the SCS to provide researchers with a way of assessing individual differences in selfcontrol techniques (Richards, 1985). The SCS consists of 36 items on a six-point scale. The total score of the scale could range from -108 to 108 . For normal populations the median score is 25 with a standard deviation of 20 (Rosenbaum, 1990). Rosenbaum refers to high-resourceful persons as those who score above the median score of 25 and those who score below 25 as less-resourceful.

\section{Pressures and Demands}

Every day external pressures and demands affect an individual's feeling state. If there are too many pressures and demands at one time, the individual may not adequately attend to these pressures and demands, and coping may be reduced (Rosenbaum, 1990). Variables concerning pressures and demands in the groups that follow include, but are not limited to, adaptive functioning, parenting styles, loneliness, self-esteem, coping, stress, self-efficacy, anxiety, and depression. 
Parent- child. Zauszniewski, Chung, Chang, and Krafcik (2002) examined family context, maternal characteristics, and individual child traits as predictors of LR in 122 school-aged children. Data were collected in face-to-face interviews and maternal functioning and automatic thoughts of the mother and child were measured. Findings were statistically significant and revealed LR did not appear to be gender dependent. Resourcefulness was not related to academic performance. The study found LR of school-aged children was greatly affected by their thought patterns. Children with more negative thinking patterns were less likely to be resourceful than those whose thinking patterns were more positive. The mother-child relationship is especially important for developing resourcefulness in the child. High maternal resourcefulness was predictive of greater resourcefulness in the child.

Chang, Zauszniewski, Heinzer, Musil, and Tsai (2007) examined the buffering effects of a child's LR in 122 pairs of children and their female caregivers. A secondary data analysis from a cross sectional design was completed. A child's LR had a direct, but not a moderating effect, on their depressive symptoms. A statistically significant moderating effect of $L R$ on the relationship between the female caregiver's depressive symptoms and the child's adaptive functioning was found, indicating a child who had a depressed caregiver but higher resourcefulness showed more adaptive functioning.

Preechawong, Zauszniewski, Heinzer, Musil, Kercsmar, and Aswinanonh (2007) used a descriptive study to examine the relationships among family functioning, self esteem, and resourceful coping in 132 Thai adolescents with 
asthma. Findings were statistically significant, revealing age was related to resourceful coping, suggesting that developmental changes during adolescence may affect the ability to cope with negative emotions. Resourceful coping was positively related to self-esteem.

Turkel and Tezer (2008) surveyed LR and perceived parenting styles in 834 Turkish high school students. Findings were statistically significant for the main effect of parenting style and level of LR. Students who perceived parents as authoritative and indulgent scored higher in LR than students who perceived parents as neglectful and indulgent.

College students. McWhirter (1997) studied LR, self-esteem, and gender in a sample of 625 college students. Statistically significant findings partly supported the role of LR predicting the experience of social loneliness. The mediating effects of gender on the relationships among LR, self-esteem, and Ioneliness were not supported.

Ginter, West, and Zarski (2001) studied situation specific coping with stress and test performance in a sample of 80 graduate education students from two universities in a prospective design. It was found that individuals who report a broad repertoire of coping skills vary their coping efforts as a function of situational demands. Findings were statistically significant; during both controllable and uncontrollable phases of a real life stressor, highly resourceful individuals reported less stress symptomatology.

Akgun and Ciarrochi (2003) applied LR to academic stress with 141 first year college students. The statistically significant findings concluded that 
academic stress was associated with a low level of academic performance, but in the overall group there was no relationship between academic stress and highly resourceful students.

Akgun (2004) surveyed 255 undergraduate college students to determine whether individuals high and low in LR differ in perceived stress levels, selfefficacy, expectations, and coping strategies. Findings indicated a significant positive relationship between LR and confidence. LR was negatively related to escape avoidance and positively related to planned problem solving.

Adults. Rosenbaum and Palmon (1984) studied helplessness, LR, and coping with epilepsy in 48 adult outpatients who experienced seizures through a survey and structured interview process. Levels of anxiety and depression, ability to cope, and perceived level of control were examined. Findings were statistically significant, confirming psychological adjustment to epilepsy is influenced by the repertoire of self-control skills, and individuals with high LR were less depressed, less anxious, and coped better with their illness.

Zauszniewski (1994a) compared health seeking resources, adaptive functioning, social interest, and living skills in 63 depressed and 63 nondepressed adults from the same community. Depressed subjects were found to be less resourceful than their non-depressed comparison group and less resourceful in identifying, developing, and using coping strategies. Social interest and LR were positively correlated with adaptive functioning. For the depressed group LR was the only significant predictor of adaptive functioning. 
Zauszniewski (1994b) examined LR, depressive symptoms, and adaptive functioning in 63 acutely depressed adult inpatients through face to face structured interviews. Depressed adults with and without familial depression differed significantly in LR and depressive cognitions. Those with a previously depressed family member were significantly less resourceful than the comparison group.

Kennett and Ackerman (1995) surveyed the relationship between LR skills and weight loss in 13 women. LR was significantly related to self-reinforcement at measurement times one and three. There was no significant difference in weight loss for high and low resourceful subjects. There was a difference in weight loss in the groups at follow-up, with highly resourceful participants loosing significantly more weight.

Zauszniewski (1995b) examined depression, health-seeking behaviors, social interest, and adaptive functioning in 126 depressed outpatients in a cross sectional, descriptive, correlational study. Findings were statistically significant. Social interest and LR were found to be more predictive of adaptive functioning than depressive symptoms. Among the depressed outpatients who reported a previous history of hospitalization for treatment of depression, both the absence of depressive symptoms and LR were predictors of adaptive functioning. Among the group of patients who did not experience hospitalization, the absence of depressive symptoms, LR, and social interest were predictors of adaptive functioning. 
Aged. Zauszniewski and Wykle (1994) compared differences in selfassessed health problems, depressive cognitions, and LR in 30 African American and 30 White functionally independent older adults. African American elders were found to be significantly more resourceful than White elders when faced with disturbing thoughts, feelings, or sensations. African American elders reported less depression than White elders.

Zauszniewski (1996) examined 120 elders to determine if there were differences in two types of resourcefulness (personal and social) in functionally independent adults. A cross-sectional, descriptive, correlational study with helpseeking behaviors, depressive cognitions, adaptive functioning, and life satisfaction was done. LR was significantly correlated with depressive cognitions, adaptive functioning, and life satisfaction. Those with higher LR scores reported fewer depressive cognitions, better functioning in daily activities, and more life satisfaction.

Zauszniewski and Martin (1999) examined the predictive relationships between indicators of the successful resolution of Erikson's eight stages of developmental tasks and LR in 60 older adults. Regression analysis demonstrated $37 \%$ of the variance in LR was explained by trust, autonomy, initiative, industry, and identity. Intimacy, generativity, and integrity were not significant. Findings suggest mastery of developmental tasks through adolescence play a key role in determining how resourceful healthy elders are in daily activities. 
Potter and Zauszniewski (2000) examined general health perception with spirituality, resourcefulness, and arthritis in a sample of 47 outpatients using a correlational, cross-sectional study. Neither spirituality, LR, or arthritis impact were predictors of health perception. The addition of spirituality to LR had no substantial influence on the health perception of participants. LR correlated highly with spirituality, indicating there may be an interactive effect between psychological and spiritual health.

Zauszniewski, Eggenschwiler, Preechawong, Roberts, and Morris (2006) examined the effects of LR training on the health of 89 elders living in retirement communities. A quasi-experimental, pre-test post-test design with repeated measures examining anxiety, depression, functional status, and self-assessed health was conducted. Greater LR was found with lower levels of anxiety and depression, but was not associated with functional status.

Bekhet, Zauszniewski, and Wykle (2007) examined milieu change and relocation adjustment in 104 elders in an exploratory study with relocation controllability, positive cognitions, and relocation adjustment. Positive cognitions had a direct positive effect on LR and relocation adjustment. LR did moderate the effects of relocation controllability on relocation adjustment. Synthesis of Research on Pressures and Demands

The importance of emotional health and behavior has been recognized as contributing to an individual's overall well-being. Rosenbaum (1990) proposed the development of LR begins early in childhood and develops throughout life. Four research findings support this proposition of LR beginning in childhood. 
Zauszniewski, Chung, Chang, and Krafcik (2002) note the impact of mothers fostering LR in their children. Turkel and Tezer (2008) recognize the importance of the parent-child relationship in fostering higher levels of LR. Preechawong, Zauszniewski, Heinzer, Musil, Kercsmar and Aswinanonh (2007) support Rosenbaum's proposition with their findings that developmental changes during adolescence may affect one's ability to cope better with emotions. In a study of older individuals Zauszniewski and Martin (1999) recognize the mastery of developmental tasks through adolescence play a key role in how elders maintain resourcefulness later in life.

The refinement of $L R$ does not end in adolescence. Resourcefulness is thought to be refined through a life-long learning process (Rosenbaum, 1990). Potter and Zauszniewski (2000) studied spirituality and LR, finding LR correlated highly with spirituality. They postulate there may be an interactive effect between the psychological and spiritual. Spiritual individuals by nature may be higher in LR.

Rosenbaum (1990) notes gender has no effect on LR. This notation is supported by Zauszniewski, Chung, Chang, and Krafcik (2002) in their study of school-age children. McWhirter (1997) also found support for this idea in his study of college students. While gender may not be an issue, Zauszniewski and Wykle (1994) found a difference in race and LR. They found African American elders were more resourceful than Whites when faced with disturbing thoughts, feelings, or sensations. 
Rosenbaum (1990) describes those who exhibit LR as able to regulate or control internal events such as emotions and cognitions that would interfere with the execution of target behaviors. This is supported by multiple researchers in varying populations. Ginter, West, and Zarski (2001) found that individuals who report a broad repertoire of coping skills could vary their coping efforts as a function of situational demands. A positive relationship between LR and confidence was noted by Akgun (2004). Rosenbaum and Palmon (1984) confirmed the psychological adjustment to epilepsy is influenced by the repertoire of self-control skills, and individuals with high LR are less depressed, less anxious, and coped better with their illness. Kennett and Ackerman (1995) found those with higher LR were able to lose more weight. Zauszniewski (1996) noted elders with higher LR scores reported fewer depressive cognitions, better functioning in daily activities, and more life satisfaction.

In college students Preechawong, Zauszniewski, Heinzer, Musil, Kercsmar, and Aswinanonh (2007) note students who are higher in LR had higher levels of self-esteem. Akgun (2004) found college students higher in LR had more confidence and problem solving abilities.

Adaptive functioning, an internal mechanism to regulate control of internal events, was assessed in several studies. Chang, Zauszniewski, Heinzer, Musil, and Tsai (2007) found children higher in LR had better adaptive functioning. Zauszniewski (1994a) found LR in adults positively correlated with adaptive functioning. These findings are again supported by Zauszniewski (1995b) in a study of depressed patients where LR was a predictor of adaptive functioning. 
Zauszniewski was also able to support the relationship of LR and adaptive functioning in a 1996 study of elderly, independent adults.

Cognitive control was measured by many researchers. Zauszniewski, Chung, Chang, and Krafcik (2002) found LR affected thought patterns. Ginter, West, and Zarski (2001) found that during periods of actual stress college students higher in LR experienced less stress symptoms. Akgun and Ciarrhochi (2003) found students higher in LR did not falter in academic performance when experiencing periods of stress. Zauszniewski, Eggenschwiler, Preechawong, Roberts, and Morris (2006) found those higher in LR had less anxiety and depression. Bekhet, Zauszniewski, and Wykle (2007) found LR had a direct effect on positive cognitions when faced with the experience of relocating.

Rosenbaum and Palmon (1984) offer that adult individuals who are more capable of self-regulating their emotional reactions are less affected by uncontrollable events. In support of this offering the researchers provided evidence that individuals with higher resourcefulness are less depressed and better able to adjust to problems, such as epilepsy. In a weight loss study Kennett and Ackerman (1995) note that individuals with higher levels of resourcefulness were more successful at weight loss and more accountable in staying with a self-directed program. Potter and Zauszniewski (2000) identify a correlation between LR and spirituality, indicating an interactive effect between spirit and mind.

Studies cited examined a variety of pressures and demands that may likely be present in or experienced by working women who are poor and 
uninsured, such as stress, anxiety, depression, and loneliness. While many of these experiences may be common, the uninsured, working, poor women remain absent in studies of LR. Studies originate from two primary disciplines: psychology and nursing. Researchers from psychology frequently use a convenience sample of college students. Researchers from nursing may use a convenience sample at times, but often recruit candidates for participation in varying age groups. All researchers consistently measured LR by use of the SCS, developed by Rosenbaum (1990).

Health and Well-Being

A general state of health and WB in this study is related to the manner in which a threat is perceived (real or imagined) and will manifest in a physiologic response related to the general state of health and WB. When recognition of calming self-statements verify the sent threat as more perceived than real there tends to be a reduction in the perception of the threat through positive feedback. The positive feedback leads to a higher level of LR. The higher level of LR is demonstrated by the individual taking actions to promote health and WB (Rosenbaum, 1990). Health and WB in the groups that follow include, but are not limited to, addictive behaviors, disease management, health related quality of life, life satisfaction, and self-care.

College students. Carey, Carey, Carnrike, and Meisler (1990) studied the relationship between LR and two common addictive behaviors of drinking and smoking in a correlational study with 175 undergraduate college students. Findings were statistically significant, revealing heavy drinkers were lower in LR 
than were light and moderate drinkers, who in turn were lower than abstainers. The findings indicated there were no significant differences in smoking and LR. Kennett, Morris, and Bangs (2004) surveyed 189 undergraduate students who were successful at quitting smoking. Addiction level, the ability to resist smoking, and motivators for quitting were examined. Findings revealed smokers were significantly less resourceful than non-smokers and successful quitters. Successful quitters were generally more resourceful and had a higher selfefficacy score than unsuccessful quitters.

Adults. Aikens, Wallander, Bell, and Cole (1992) studied daily stress variability, regimen adherence, and metabolic control in 62 Type I diabetics. Stress and LR did not interact to predict metabolic control. LR was positively correlated with poor metabolic control.

Toomey, Seville, Mann, Abashian, and Wingfield (1995) examined LR in 87 adult patients from an outpatient chronic pain clinic in a cross sectional, retrospective, correlational design. Levels of pain, pain control measures, and health utilization measures were examined. The statistically significant findings showed patients with chronic pain reported adequate ability to engage in LR, but with considerable individual variation.

Picot, Zauszniewski, and Delgado (1997) explored the relationships among caregiver status, demands, resources, and cardiovascular responses in 18 African American caregivers and 24 non-caregivers with and without hypertension. No statistically significant correlations were found between caregiver status, daily hassles, total chronic conditions, total anti-hypertensives, 
$\mathrm{LR}$, and vital signs among participants. Both groups had comparable levels of LR.

Zauszniewski and Chung (2001) examined the effects of severity of symptoms of coexisting diabetes, diabetic symptoms, health practices, and depression on health practices of young and middle aged women and the effects of LR with 90 diabetic women in a cross sectional descriptive study. Higher LR had a significant direct effect on health practices and partially mediated the effects of depressive symptoms. No effect was found with diabetic symptoms, and health practices.

Pedro (2002) examined LR and quality of life for 62 long-term breast cancer survivors in a descriptive correlational study. Health related quality of life, self-esteem, and social support were examined. The findings were statistically significant and LR was found to be inversely related to health related quality of life. It was explained that higher levels of health related quality of life may allow the individual to be less resourceful.

Rosswurm, Larrabee, and Zhang (2002) studied LR in 106 family caregivers of dependent elderly adults using a quasi-experimental, time-series design. Caregiver competence and knowledge were examined. The experimental group perceived themselves as more competent after receiving LR training and their level of LR improved, showing a trend toward positive change. Improvement in LR indicated family caregivers in the experimental group had positive selfevaluations and were more effective problem solvers. 
Zauszniewski, McDonald, Krafcik, and Chung (2002) examined acceptance of diabetes, positive cognitions, and resourcefulness in 82 diabetic women in an outpatient setting. A cross sectional, descriptive study was completed. Depression, positive cognitions, and diabetes acceptance were examined. Findings were statistically significant and concluded that positive cognitions and depressive symptoms were significant antecedents of $L R$. Positive cognitions mediated the effects of depressive symptoms on LR.

Aged. Zauszniewski (1997a) examined teaching LR skills to small groups of older adults in a community setting using a quasi-experimental pilot study. The two groups consisted of an experimental group of 20 elders and control group of 17 elders. Anxiety, depression, adaptive functioning, and life satisfaction were measured after the completion of a six week small group intervention. The findings were statistically significant that LR training was effective in teaching skills of resourcefulness to older adults. After receiving the LR training intervention, the healthy elders in the treatment groups showed improvements with measures of adaptive functioning and life satisfaction, while those in the control group showed no changes.

Zauszniewski, Chung, and Krafcik (2001) examined the relationships between LR, health self-determinism, and help responses in 137 chronically ill elders in a cross sectional study. The study included a self-report of chronic conditions, health self-determinism, help responses, sickness and physical impact. Elderly women were more resourceful than men. African American elders 
were more resourceful than White elders. African American elders with less chronic conditions had higher LR.

Boonpongmanee, Zauszniewski, and Morris (2003) examined LR, prenatal self care, and depression in 156 pregnant women with HIV using a predictive model design. The relationship between LR and health care practices was statistically significant. Individuals with scores higher in LR showed higher adaptive functioning than those with lower scores.

Synthesis of Research on Health and Well-Being

Physiologic variables are defined as those variables related to a general state of health and WB. The manner in which a threat is perceived (real or imagined) will manifest in a physiologic response related to the general state of health and WB. Rosenbaum (1990) states the real or perceived threat results in a disruption followed by a shift in attention toward one's own behavior. It is how this disruption is recognized by the individual whether a response is generated. Zauszniewski (1995a) conceptualized LR as a positive health seeking behavior learned through life that helps to attain, maintain, or regain health and is able to be taught. This review examined a variety of physiologic threats.

How higher levels of LR impact the management of chronic medical problems or habits has been examined by several researchers. Carey, Carey, Carnrike, and Meisler (1990) found a relationship between drinking and LR. Those who were able to drink lightly or abstain had higher levels of LR than heavy drinkers. Kennett, Morris, and Bangs (2004) report similar findings in 
smokers. Those with higher LR were able to successfully quit when compared to smokers with low LR. Both of these studies examined college students.

Toomey, Seville, Mann, Abashian, and Wingfield (1995) found adults with higher levels of LR had better pain control. Zauszniewski, Chung, and Krafcik (2001) report African American elders with less chronic medical problems had higher levels of LR. Zauszniewski's position that LR is able to be taught is found in her 1997 study where elders with LR training had higher adaptive functioning and life satisfaction. Rosswurm, Larrabee, and Zhang (2002) support these findings with their results, noting family care givers who were provided with LR training had positive self-evaluations and were more effective problem solvers.

WB is an important consequence of health, defined as a reflection of the level of satisfaction that a person gathers and assimilates from life (Campbell, Converse, \& Rodgers, 1976). WB has been measured by several researchers in terms of adaptive functioning and how well an individual is able to manage once a threat is recognized as real. Zauszniewski, McDonald, Krafcik, and Chung (2002) report those with higher LR had more positive thoughts and better acceptance of diabetes, allowing them to be more responsible in managing their chronic problem. In a study of diabetic women Zauszniewski and Chung (2001) found higher LR had a direct effect on health practices in managing their diabetes. Boonpongmanee, Zauszniewski, and Morris (2003) found a supporting relationship between health care practices and LR in pregnant women with HIV. Individuals with higher LR also demonstrated higher adaptive functioning. 
Studies originated from two primary disciplines: psychology and nursing. Researchers from psychology frequently use a convenience sample of college students. Researchers from nursing may use a convenience sample at times, but often recruit candidates for participation in varying age groups. Studies cited examined a variety of physiologic factors that may likely be present in or experienced by working women who are poor and uninsured, such as addictive behaviors of drinking or smoking, chronic pain, chronic medical problems, threats to health and life such as cancer and HIV. Working women who are poor and uninsured often find themselves in the role of family caregivers, caring for children, parents, and other relatives. Addictive behaviors, such as smoking, may be prevalent in their lives. They, or those they care for, may experience chronic medical problems, pain, or terminal illness, all in the face of lacking resources such as insurance. All researchers consistently measured LR by use of the SCS, developed by Rosenbaum (1990).

\section{Uninsured}

Poor and uninsured individuals struggle to endure in the current precarious health care and economic crisis in the United States. The experience of being poor and without medical insurance is a formidable barrier to health care for many Americans. National surveys estimate the number of uninsured individuals ranged from 20 to 80 million persons with a "point in time" range of non-elderly uninsured adults from 41 to 46 million (Kaiser Family Foundation, 2006). Despite an improving economy between 2004 and 2006, the number of uninsured grew by an additional 3.4 million (Kaiser Family Foundation, 2007). 
Two-thirds of the uninsured are individuals and families who meet the federal definition of poor or near poor (Kaiser Family Foundation, 2007).

Women and children constitute the largest and most vulnerable group in society (Johnson, 2001) and experience either a total lack of health care services or significant barriers to accessing services (Mundt, 1998). Medicaid provides coverage to some but not all low-income individuals and families, based on income and categories of eligibility (Kaiser Family Foundation, 2007). Individuals who are not covered by employer-sponsored health insurance are not automatically eligible for Medicaid or public health insurance (Seccombe \& Amey, 1995). The majority of uninsured adults (75\%) have gone without coverage for at least one year. Those who are ineligible for Medicaid and not offered affordable employer-sponsored coverage are often left uninsured for long periods of time, because individual coverage is either unaffordable or unavailable to them (Kaiser Family Foundation, 2007). The review of the uninsured literature will be structured to address the consequences of LR in the study of well-being and health.

Well-being

The concept of WB in the uninsured has been cited in the literature. Campbell, Converse, and Rodgers (1976) focus their description of WB as an expression of a cumulative, global satisfaction with specific domains of life experience. Much is written about the perils of being uninsured, which may influence the general sense of well-being and future consequences to an individual. 
The Kaiser Family Foundation (2007) states almost half of all uninsured non-elderly adults have a chronic condition. Nadkarni (2004) provides a description of the future concerning the impact of chronic illness, which affects WB. Over 100 million Americans currently have a chronic medical condition, and this rate is projected to increase to 134 million by 2020 . Forty-four percent of Americans will have multiple chronic conditions. By 2020, one out of every six individuals over age 65 will become limited by chronic conditions. Nadkarni (2004) goes on to state poor, medically underserved, and minority patients experience significantly worse health outcomes. Living with chronic medical problems and poor health outcomes may negatively influence an uninsured individual's general sense of well-being.

When WB is studied, qualitative, rather than quantitative, data are routinely gathered (Collins, 2005; Koziol-McLain, Price, Weiss, Quinn, \& Honigman, 2000; and Orne, Fishman, Manka, \& Pagnozzi, 2000;). A study by Collins (2005) involved women from a food co-op who met weekly. The women equated WB with quality of life. Qualities of a good life that promote WB include relationships with family and friends, enough savings to manage emergencies, intangible qualities such as love, happiness, religion, success, no stress, selfesteem, and courage. WB was not solely defined in material terms by this group. Poor quality of life was described as stress and worry that was identified with consequences such as lack of income leading to not enough food, poor housing, and poor health. 
Koziol-McLain, Price, Weiss, Quinn, and Honigman (2000) explored what made uninsured patients seek emergency room care in a phenomenological study. Two themes emerged from participants reflecting WB and quality of life. The first theme was "toughing it out," with patients describing their experience of doing the best they could with their suffering for as long as possible before seeking help. Another theme of "symptoms overwhelming self-care measures" described how patients did the best they could with available resources to manage their problem, but in the end their over all WB was compromised to the point of requiring outside help.

In another phenomenological study Orne, Fishman, Manka, and Pagnozzi (2000) identified several pertinent themes reflecting WB and quality of life. A theme of "a marginalized life" emerged, where participants viewed themselves as being vulnerable on all fronts and experiencing limits, loss and hard times. A second theme of "up against rocks and hard places" captured feelings of working and not holding insurance. This theme represented a poor sense of WB as participants reflected upon their experience of not affording insurance, needing care, and not being able to afford medications, medical visits, or costs of testing. The theme of "getting by - more or less" reflected participants thoughts of knowing they were getting by, yet feeling a bit lucky as their situations could get worse.

The percentage of people covered by employee-based health insurance has decreased (Holahan \& Wang, 2004), thus affecting WB by hindering access to care. More than two-thirds of uninsured people work full time or come from 
families in which at least one person works full time. In $2003,60.4 \%$ of Americans were covered by private employer insurance plans. In the same year, employee contributions to premiums rose, deductibles and out-of-pocket maximum expenses increased, co-pays on the part of the employee increased, and many employers reduced covered services (Weinick, Byron, \& Bierman, 2005). The past decade has shown a decline of slightly less than one percentage point per year in the rate of employee-sponsored insurance (Holahan \& Cook, 2009). The majority of uninsured employees are either not offered health benefits through their employer, are not eligible for health benefits, or cannot afford the out-of-pocket health benefit premiums (Hoffman, 2007). Those who are employed and have been receiving employee-sponsored health benefits have seen significant changes in benefits, contributing to a lack of affordability of their portion with more co-pays, increasing premiums, and higher co-insurance (Mundinger, Thomas, Smolowitz, \& Honig, 2004). Some of those affected with benefit changes or lost benefits find ways to make contact with a primary care provider, and those who cannot connect with a primary care provider attempt to manage their health problems at home (Huttinger, Schaller-Ayers, \& Lawson, 2004). Persons who find themselves uninsured do not routinely use health services, make physician visits, or have prescriptions filled (Cheng, 2005).

The uninsured are three times as likely as those with health coverage to live in a household that is having difficulty paying basic monthly expenses such as rent, food, and utilities. The significant stressor of juggling to meet basic needs may affect an individual's well-being. Medical bills for even minor 
problems can mount quickly, with a negative reflection on an individual's credit history (Shipler, 2005). Hospitals frequently charge uninsured patients two to four times what health insurers and public programs actually pay for hospital services (Kaiser Family Foundation, 2007).

Health

Personal health practices have been shown to be important determinants of overall health. The WVBRFSS has collected information on the health practices of West Virginians since 1994. The survey is a state-based system of that collects information on health risk behaviors, preventive health practices, and health care access primarily related to chronic disease and injury (CDC, 2010). The survey was established in 1984 (CDC, 2010) and is done in collaboration with the West Virginia Bureau for Public Health and the Centers for Disease Control and Prevention (WVBRFSS, 2009). The survey enables the state to determine the prevalence of certain risk factors and health conditions among adults. The need for this data was identified when research showed personal health behaviors played a role in premature morbidity and mortality. The goal is to collect data on actual behaviors, rather than on attitudes or knowledge (CDC, 2010). West Virginia ranked 2nd highest nationally in 2006 in reporting the general health of adults as either "fair" or "poor." Almost one-fourth of West Virginia adults $(22.5 \%)$ consider their health to be either "fair" or "poor." "Fair" or "poor" health is most common among groups of adults who are the oldest, least educated, or with lower household incomes (WVBRFSS, 2009). 
Individuals who are uninsured often face barriers to health care and are less likely to receive primary care services with the same frequency as those who are insured (Orne, Fishman, Manka, \& Pagnozzi, 2000). Access to care and achieving specific health indicators is difficult for individuals without health insurance, who work but do not have employee health benefits, cannot afford health benefits, or who live in an underserved area (Hartley, 2002). Having health benefits, a higher income, and a primary care provider are strong predictors that a person will receive adequate health care and necessary special equipment (Hartley, 2002), and these predictors are usually not a part of the lives of the uninsured. Leight (2003) recognized the value of achieving health indicators by recommending targeted strategies for primary, secondary, and tertiary levels of prevention.

Many patterns have emerged concerning the use of health services by the uninsured. Uninsured individuals use health services less frequently and opt to postpone medical procedures. When actually presenting for care, the health problems of the uninsured are often more severe, and the emergency department is often the provider for care by default (Orne, Fishman, Manka, \& Pagnozzi, 2000; Mundinger, Thomas, Smolowitz, \& Honig, 2004). The uninsured are less likely to receive preventative care such as immunizations, family planning, prenatal care, breast exams, and mammography (Orne, Fishman, Manka, \& Pagnozzi, 2000). In conjunction with services, the uninsured are less able to afford necessary prescriptions and follow through with treatment recommendations (Hoffman, 2007). Lack of insurance is associated with 
increased mortality. Persons without insurance are more likely to be hospitalized for conditions normally treated out of the hospital or avoided altogether (Ford, Will, DeProst Ford, \& Mokdad, 1998). Adults in late middle age may be particularly vulnerable to adverse health consequences that result from a lack of health insurance and decreased access to care leading to a higher prevalence of chronic disease (Baker, Feinglass, Durazo-Arvizu, Witt, Sudano, \& Thompson, 2006).

In a study that examined how to meet the health care needs of vulnerable populations, Johnson (2001) found study participants recommending the following to improve overall health care: provide lower cost insurance, improve transportation, and lower the cost of medications and clinic visits. Other issues that were perceived as barriers included provider gender, long wait times, difficulty scheduling appointments, and disrespectful treatment by office staff and providers. Concerning barriers, Nadkami (2004) found several similar and dissimilar responses. Included in the findings indicating barriers to care were access to providers, medications, exercise, proper diet, information, and transportation.

\section{Working Poor}

Literature concerning the working poor commonly stems from government, business, and economic sources. A multitude of facts and statistics exist presenting a snap shot of a working, poor woman. Several characteristics influence the likelihood of working and being poor. Newman (1996) disputes a stereotypical image of poor people as shiftless, noting the working poor often 
hold jobs no one else wants. The earnings from these jobs are meager. A U.S. Department of Labor report (2007) states working full-time (35 or more hours per week) lowers a person's likelihood of being poor, yet six out of ten of the working poor held a full-time job in 2005 . Women are more likely than men to be among the working poor (Labor Month in Review, 2003). Achieving higher levels of education reduces the incidence of being among the working poor. Those with more education have greater access to higher paying jobs than do those with less education. Type of occupation has an impact. Management, professional, and related occupations had the lowest working poor rate (1.9\%). Service occupations have the highest working poor rate (11.2\%). Those working in natural resources, construction, and maintenance occupations had an aboveaverage rate of $7.3 \%$ (Labor Month in Review, 2006). The working poor rate is higher among families with children. Among families headed by women with children under age 18 , the working poor rate was $22.6 \%$. For families headed by men with children the rate was $12.4 \%$ (U.S. Department of Labor, 2007). Dyk (2004) reviewed poverty in the U.S. by region and notes West Virginia is grouped into the Southern states region with Arkansas, Mississippi, and Louisiana having a poverty rate of $18 \%$.

Conlin and Bernstein (2004) recognize differences between those who are working and poor and those who are working and less poor. They note a missed bus, a stalled engine, or a sick child all mean the difference between keeping a job and getting fired. The working poor find themselves victims of employers as they reduce work hours and pay or force employees to work off of the clock and 
go uncompensated. Shipler (2005) describes the hurdles of the working poor as they gain and lose employment, struggle to keep a checking account (often unable to keep the required monthly balance), rely heavily on yearly income tax returns, and must decide which monthly bills to pay so there is enough money left for food and rent. This information supports Dyk's (2004) writings that working poor families are different from middle and upper income families because of their exposure to and experience of substantial stressors. These stressors include low-wage jobs, low education levels, greater barriers to obtaining social services, unstable and unsafe living arrangements, family and community violence, and substance abuse.

Seccombe and Amey (1995) identify those who are working and poor without insurance typically do not see a health provider until conditions become urgent. The researchers discuss an assumption that a "job is a ticket to a better life" is not always true with respect to insurance coverage. Zagorsky (1999) notes poverty affects more females than males, and individuals with health problems comprise a larger population of the working poor. Those who suffer from working in poverty with poor health are likely to remain in this situation.

\section{Summary}

There is a gap in the literature concerning LR in working women who are poor and uninsured. To date no evidence could be found in the literature relating LR to women, who are poor, and are uninsured. The gap provided the impetus for studying LR in this group. The plight of women is different than that of men, and women often have additional responsibilities of caring for others while 
working the best they can to get by. Poverty is greater for women than for men (Spriggs, 2007).The number of uninsured continues to grow (Kaiser Family Foundation, 2006) and women tend to be in lower wage jobs (Monthly Labor Review, 2003), and experience either a total lack of health care or significant barriers to accessing care (Mundt, 1998). 
Chapter 3: Methodology

This chapter provides an overview of the research questions, study design, sample, setting, measurement of concepts, procedure for data collection, and analysis strategies. The purpose of the study was to describe the interrelationships between learned resourcefulness (LR), health, and WB in working women who are poor and uninsured.

Research Questions

1 What are the demographics of working women who are poor and uninsured?

2 How is health status described in working women who are poor and uninsured?

3 How is LR described in working women who are poor and uninsured?

4 How is well-being described in working women who are poor and uninsured?

5 What is the relationship between LR and well-being?

6 How do LR and significant demographic variables work together to predict well-being?

7 How do LR and significant demographic variables work together to predict perception of general health?

\section{Design}

A cross sectional research design was used to determine the relationships between LR, health status, and WB in working women who are poor and uninsured. 


\section{Sample}

A convenience sample of 136 women who held at least part time employment, met the federal definition of poverty, received care at a free clinic, and held no health benefits were studied. Participants were recruited from an established, free health clinic in West Virginia. The sample size was calculated by two standard formulas $(N \geq 50+8 m$ and $N \geq 104+m$, where $m$ is the number of predictors), as no prior data are available as a precedent in this population. A simple rule applies with both calculations being completed and the calculation yielding the largest number of cases is chosen. This method assumed a medium effect size with a power of 0.8 and an alpha of 0.05 (Tabachnick \& Fidell, 2007). This study used 9 variables to predict well-being in working women who are poor and uninsured.

The inclusion criteria consisted of: 1) age greater than 25 years but less than 65 years; 2) female; 3) having no health benefits; and 4) had an income level below $100 \%$ of the federal poverty level.

\section{Setting}

An established West Virginia free medical clinic was the setting for data collection. The clinic opened in 1986, providing a variety of health care services free to individuals meeting admission requirements. Services offered include nurse practitioner clinics, physician clinics, specialty clinics, social services, health education, family planning, breast and cervical cancer screening, and individual or group counseling. A pharmacy is on-site and approximately 90,000 
prescriptions were filled last year. The clinic estimates it is currently caring for about 11,225 patients.

\section{Measurement of Concepts}

\section{Learned Resourcefulness}

Conceptual definition. LR is an acquired repertoire of behavioral and cognitive skills with which a person is able to regulate internal events such as emotions and cognitions that might otherwise interfere with the smooth execution of target behaviors (Rosenbaum, 1990). Rosenbaum (1990) states LR refers to what people do when stressful circumstances call for self-direction. Rosenbaum $(1980,1990)$ defined LR as a collection of skills, primarily cognitive, that are used to control the undesirable effects of certain thoughts, feelings, or sensations so that daily activities will continue undisturbed. LR comprises a cognitivebehavioral repertoire of skills that are used to control the effects of negative thoughts, feelings, and sensations on a daily task performance (Rosenbaum \& Jaffe, 1983).

Operational definition. The Self Control Schedule (SCS), developed by Rosenbaum (1990), is the sole instrument available to measure LR. The SCS is a 36 item self-report instrument using a six-point Likert-type scale. The SCS is a uni-dimensional measure to assess four types of self-control that comprise LR: use of cognitive strategies, use of problem-solving strategies, the ability to delay immediate gratification, and a belief in one's ability to perform. The SCS has been administered to a broad range of individuals, though no evidence has been found relating LR to working women who are poor and uninsured. 
The SCS consists of a normative reference of measurement. In Rosenbaum's (1980) original assessment, means for the samples of 162 student participants ranged from 23-27, with a standard deviation of $21-25$ with no differences between sexes. Redden, Tucker, and Young (1983) found similar means with 989 college students in their study. Richards (1985) found higher means in his group of 121 college students, ranging from 36.5 to 38.1 . He attributed the difference by noting his subject groups were from a private, religious university with a college honor code and an even more demanding religious value system requiring a higher degree of self-control.

For this study the original 36 item SCS was used. It is currently the only instrument available to measure LR and has been used by all researchers measuring this concept. Subjects were given the instrument as part of a packet and asked to read and compete the survey. The simplified measure of gobbledygook (SMOG) is a formula that gives a readability level for written material. Readability is an attempt to match the reading level of written material to the "reading with understanding" level of the reader The SMOG level for this instrument is rated at 9.89, indicating some high school education is required when reading (National Literacy Trust, 2008).

Scoring. Subjects mark the degree to which each item describes their behavior, ranging from -3 to 3 without a zero point indicating a neutral response. The total score may range from -108 to 108 (Rosenbaum, 1980). Rosenbaum (1980) notes for normal populations the score is usually a median of 25 with a standard deviation of 20 . Reverse scoring is required for eleven particular items. 
Once completed all scores are summed (Rosenbaum, 1980). Those who rate above the median score of 25 with the SCS are referred to as high resourceful individuals and those who score below the median score are referred to as less resourceful individuals (Rosenbaum, 1988).

Reliability. In the original 1980 study test-retest reliability was addressed. The difference between the means of the first testing (25.1) and second testing experience (24.4) was deemed not significant with a $p$ value of $>0.5$. Also noted were the Pearson Correlation scores on the two testing periods of .86 with a $p>$ .01 , indicating a fairly high stability of test scores over a four week period. Alpha coefficients reflecting internal consistency ranged from .78 to .84 and were considered satisfactory (Rosenbaum, 1980). In early psychometric testing Redden, Tucker, and Young (1983) found a similar alpha coefficient of .82. The Cronbach's alpha for LR data gathered in this study was .77, indicating a good estimate of reliability for this study.

Validity. To evaluate construct validity Rosenbaum (1980) used Rotter's I-E scale which focused on the extent to which one believes that reinforcement is a function of one's behavior. The Pearson $r$ between the two scores was -.40, indicating the more a subject reported on the use of self-control the less belief in external control of behavior. The second scale Rosenbaum (1980) employed was the Irrational Beliefs Test. All correlations were moderate to low and significant. Subjects who reported greater application of self-control methods were less likely to hold irrational beliefs. Factor structure was assessed by Redden, Tucker, and Young (1983) for males and females using college students. The researchers 
found the obtained coefficients were reliable and acceptable for males, females, and the total sample. The factor structure was found to be considered "not strong" and the authors suggested proceeding with caution to determine a clear, strong factor structure. Item analysis indicated a strong degree of homogeneity reflecting adequate internal consistency. The authors provide comments that the SCS is in the early stages of development and appears promising for a valuable self-report measure. Richards (1985) further supported construct validity with significant correlations between the SCS and the Manifest Anxiety scale $(r=31$, $p=.002)$

Well Being

Conceptual definition. Campbell, Converse, and Rodgers (1976) focus their description of WB as an expression of a cumulative, global satisfaction with specific domains of life experience. Their work began with an examination of "happiness" as a social indicator. As the work evolved and moved along they settled on an assessment of one's life in general, or an overall sense of WB.

Operational definition. In a large study of Americans, Campbell, Converse, and Rogers (1976) provided a structured interview questionnaire to a random sample of 2,160 Americans with the results leading to the development of the Index of Well-Being (IWB), a nine-item semantic-differential scale. Initial development began with ten items and the instrument currently in use consists of nine items - eight items measuring aspects of global quality of life and the final item rating overall satisfaction with life. Semantic differential was developed by Osgood and colleagues in 1957 as a mode of exploring the connotative meaning 
which any object, concept, or situation may have for an individual. The technique involves a battery of opposite adjectives placed at extremes on a 7-point scale with respondents being asked to place a mark on the scale (Campbell, Converse, \& Rogers, 1976).

The IWB consists of a normative reference of measure. Reed (1987) noted means ranging from 10.27 to 10.36 in 100 terminally ill patients. In a 1995 study of 31 long-term cancer survivors Dirksen noted means of 12.10. In a 2002 study of 58 heart failure patients Berry, Baas, Fowler, and Allen noted means of 10.8 with a range of 3.9 to 14.7 . Fowler and Baas (2006) noted means of 7.95 in their study of 42 patients with chronic kidney disease.

For this study the original nine item IWB was used. Subjects were given the instrument as part of a packet and asked to read and compete the survey. The SMOG level for this instrument is rated at 8.77 , indicating a junior high school reading level is required (National Literacy Trust, 2008).

Scoring. The instrument is designed to obtain a global measurement of WB. The score is calculated by obtaining the mean of the first eight questions and adding the final item which is weighted. Scores can range from 2.1 to 14.7.

Reliability. Original stability determinations were documented by Campbell, Converse, and Rogers in 1976. A test-retest reliability coefficient of .53 was obtained in an eight month re-test of a small sub sample of original participants. Cronbach's alpha was initially reported as .89 by these researchers and developers. Braden (1990) obtained an alpha of .95 in her study of 396 individuals with a chronic illness. Baas, Beery, Fontana, and Wagoner (1999) 
obtained an alpha of .95 in their study of 138 adults with heart failure. The Cronbach's alpha on data on WB in this study was .75, indicating a good estimate of reliability.

Validity. Campbell, Converse, and Rogers (1976) supplied data concerning construct validity. Using factor analysis the instrument developers noted eight pairs have loadings on one factor in the range of $.65-.79$. Dirksen (1990) provided an estimate of construct validity through factor analysis using principal components, revealing that all scale items loaded into one factor, explaining $61 \%$ of the variance. Concurrent validity with a level of .35 was supported by Campbell, Converse, and Rogers (1976).

Health Status

Conceptual definition. Health status is defined as physical actions or cognitive skills with which one regulates internal events such as emotions or cognitions by the execution of specific responses (Rosenbaum 1990).

Operational definition. Selected health indicators from the West Virginia Behavioral Risk Factor Surveys (WVBRFS) $(2007,2009)$ were used in this study to measure health status. Questions selected provided gauges of health in uninsured, working women. Each year since 1984 West Virginia has measured health indicators in conjunction with a larger effort through the Centers for Disease Control and Prevention (CDC). The indicators examined may change somewhat from year to year and each indicator may not be examined yearly. The survey is conducted by telephone and the sample is selected by random digit 
dialing. The total number completing the survey in the 2007 reporting year was

3,390 and slightly larger in 2009 with 3,675 completing the survey.

The specific questions chosen from the survey support the study aims and reflect actions promoting health and WB. Questions included:

1. Has there been a time in the last year that you have needed medical care but could not afford it? Yes or no

2. Do you have a person you think of as a personal doctor or health care provider? Yes or no

3. Would you say that in general your health is excellent, very good, good, fair, or poor?

4. Have you ever been told by a doctor, nurse, or other health provider that you have high blood pressure or high blood sugar (diabetes)? Yes or no

5. Do you smoke? Yes or no

6. Have you had a PAP test in the last three years? Yes or no

7. In general, how satisfied are you with your life? Very satisfied, satisfied, dissatisfied, or very dissatisfied.

Demographic Characteristics

Demographic characteristics assessed included age, gender (confirmation of female), ethnicity, marital status, educational level, residence status, number living in the household, number of jobs currently held, and insurance status.

Demographic questions were as follows:

1. How old are you?

2. Do you work?

3. What is your gender (to confirm female)?

4. What is your ethnic background? 
White; African American; Asian; Hispanic; Native American; other.

5. What is your marital status?

Single; married; divorced; separated; widowed; significant other.

6. How far were you able to go in school?

Completed middle school; some high school; graduated high school; obtained GED; some college / technical school; completed college / technical school; some graduate school; completed graduate school.

7. How many people live with you?

Spouse; children; family members; others.

8. Where do you currently live?

Own home; rent home; doubled up in a home with family or friend; homeless, live on the street; homeless, live in a shelter; homeless, live with family or friend.

9. Have you ever held health insurance?

If yes to health insurance, how many years since you were last covered?

Procedure for Data Collection

The study was approved by the West Virginia University Institutional Review Board (IRB) prior to implementation. It was expected that most participants would meet inclusion criteria because they were patients at a clinic serving the targeted population. Posters were placed in the patient waiting room, near the pharmacy, and in the exam rooms describing the research project. The investigator was on sight to provide survey packets to interested subjects. When participants indicated their interest in the study an envelope containing a cover 
letter, the SCS (Appendix A), the Index of Well-Being (Appendix B), health indicator questionnaire (Appendix C), demographic questionnaire (Appendix D), two dollars, and a pen were handed to the participant if they met the inclusion criteria. The cover letter described the purpose of the research, the voluntary nature of participation, the option to skip any or all of the survey items, and strategies to maintain both the anonymity of the participant and the confidentiality of the data. The surveys did not contain any identifying information or information that could connect the patient to a survey set. The sealed survey envelop was returned to the investigator at the time of the visit and the participant was instructed to keep the two dollars and the pen. No identifying information was on the sealed envelopes. The data collection spanned the weeks between July 27 and August 17, 2009.

All data was transported from the clinic to the investigator's home office. Data were entered and analyzed using the Statistical Package for Social Sciences (SPSS), version 17, computer software program. All data were reviewed and entered by the investigator. The computer was accessed by the investigator only. Procedure breakdown was as follows:

1. Clinic patient read poster and approached investigator or clinic staff if they desired to participate. Investigator verified patient met inclusion criteria.

2. Participant was given an envelope with a cover letter explaining the study and other required information, all survey instruments, an unadvertised two dollar incentive, and a pen. 
3. The participant was allotted time to complete the surveys during the initial new patient intake session, while waiting to see the health care provider, or after seeing the health care provider. Once surveys were complete the participant placed all papers back in the envelope and returned envelope to the investigator or clinic staff. Participants were to keep the two dollar cash incentive and the pen.

4. Survey envelopes were collected by the investigator and transported to the investigator's home office.

5. Data were analyzed using the Statistical Package for Social Sciences (SPSS).

Analysis

The analysis strategy for each research question was as follows:

1. What are the demographics of working women who are poor and uninsured?

a. Frequency tables for categorical variables

b. Descriptive statistics such as median, mean, standard deviation, and ranges for continuous demographic variables

2. How are health indicators described in working women who are poor and uninsured?

a. Frequency tables of responses for each health indicator

b. Chi-square with categorical demographics (ethnicity, marital status, education, residence, insurance status) for each health indicator

c. $t$-test with continuous demographic variables (age, number in household) for each dichotomous health indicator (medical care, health 
care provider, chronic illness, smoking, PAP test, life satisfaction, and general health status)

3. How is LR described in working women who are poor and uninsured?

a. Descriptive statistics such as median, mean, standard deviation, range of LR

b. Tests to analyze differences in LR by demographic variables

i. ANOVA with categorical demographic variables with more than two levels (marital status, education, residence)

ii. Independent $t$-test with dichotomous variable of insurance status

c. Tests to analyze differences in LR by health indicators

i. Independent $t$-tests with dichotomous health indicator variables (needed medical care, have a health care provider, have high blood pressure or diabetes, smoking, PAP test, general health status, and life satisfaction)

d. Correlation of LR with age and number in household

4. How is WB described in working women who are poor and uninsured?

a. Descriptive statistics such as median, mean, standard deviation, range of WB

b. Tests to analyze differences in WB by demographic variables

i. ANOVA with categorical demographic variables with more than two levels (marital status, education, residence) 
ii. Independent $t$-test with dichotomous variable of insurance status

c. Tests to analyze differences in WB by health indicators

i. Independent $t$-tests with dichotomous health indicator variables (needed medical care, have a health care provider, have high blood pressure or diabetes, smoking, PAP test, general health status, and life satisfaction)

d. Correlation of WB with age and number in household

5. What is the relationship between LR and WB?

a. Correlation

6. How do LR and significant demographic variables work together to predict WB?

a. Multiple regression with well-being as the response variable in a model with LR and significant demographic variables (age, ethnicity, marital status, education level, residence, number in the home, and insurance status) as predictor variables.

7. How do LR and significant demographic variables work together to predict perception of general health?

a. Multiple regression with general health perception as the response variable in a model with LR and significant demographic variables (age, ethnicity, marital status, education level, residence, number in the home, and insurance status) as predictor variables. 
Chapter 4: Results

This chapter reports the results of the cross-sectional study which examined the interrelationships between learned resourcefulness (LR), health status, and well-being (WB) in working women who are poor and uninsured. Prior to analysis, data were cleaned and examined for outliers or impossible values. This was completed by running frequencies and descriptive statistics and visually scanning for errors, missing data, and patterns of missing data. The summary provides a frequency table for categorical variables and descriptive statistics for continuous demographic variables. Findings will be presented in the order of each research question.

\section{Research Question One}

What are the demographics of working women who are poor and uninsured?

There were 132 participants in the study. It was originally determined a sample of 122 participants was required to provide an effect size with a power of 0.8 and an alpha of 0.05 . All of the participants were female and currently working. Their age ranged between 25 and 65 years, with a mean age of 45.11 years and standard deviation of 10.48 . One hundred twenty six (95.5\%) of the participants were white, three (2.3\%) were black, two (1.5\%) were Hispanic, and one (0.8\%) was Asian. Marital status of the sample included 36 (27.3\%) participants who were single, 54 (40.9\%) were married, 29 (22\%) were divorced, four $(3 \%)$ were separated, four (3\%) were widowed, and five (3.8\%) had a significant other. Educational level of the sample showed one participant $(0.8 \%)$ had no schooling, two (1.5\%) completed middle school, 21 (15.9\%) had some 
high school, 43 (32.6\%) graduated high school, 17 (12.9\%) earned a GED, 32 (24.2\%) had some college or technical school, 14 (10.6\%) completed college or technical school, one $(0.8 \%)$ had some graduate school, and one $(0.8 \%)$ completed graduate school. Living arrangements were that nine $(6.8 \%)$ participants identified themselves as homeless, 11 (8.3\%) were doubled up with a family member or friend, 46 (34.8\%) were renters, and 66 (50\%) owned their home. Participants were asked the number of people who lived with them and results ranged from zero to six, with a mean of 2.08 and standard deviation of 1.55. Concerning health insurance, $83(62.9 \%)$ report holding health insurance at some point in their life and 48 (36.4\%) report they have never held health insurance.

After examination of the initial findings several variable categories were collapsed to facilitate testing in the research questions. The variable of marital status, which initially contained six categories, was collapsed to three categories. Collapsed categories included those who are single; those divorced, separated, or widowed; and those who are married or with a significant other. The variable on education originally contained eight categories and was collapsed into three categories noting those who did not complete high school, those who completed high school or earned a GED, and those who had at least some technical or college level courses. The variable asking where participants lived originally contained four categories and was collapsed into three categories and included being homeless (includes those doubled up with a family or friend), renting, or owning a home. The variable of race was not utilized in analysis as race was 
overwhelmingly white (95.5\%).Table 2 provides an overview of the general demographic information.

Table 2: Description of Demographic Information

\begin{tabular}{|c|c|c|}
\hline $\begin{array}{l}\text { Demographic Variable } \\
n=132\end{array}$ & Frequency & Percentage \\
\hline \multicolumn{3}{|l|}{ Ethnicity } \\
\hline White & 126 & 95.5 \\
\hline African American & 3 & 2.3 \\
\hline Asian & 1 & 0.8 \\
\hline Hispanic & 2 & 1.5 \\
\hline \multicolumn{3}{|l|}{ Marital Status } \\
\hline Single & 36 & 27.3 \\
\hline Married & 54 & 40.9 \\
\hline Divorced & 29 & 22.0 \\
\hline Separated & 4 & 3.0 \\
\hline Widowed & 4 & 3.0 \\
\hline Significant Other & 5 & 3.8 \\
\hline \multicolumn{3}{|l|}{ Education } \\
\hline No schooling & 1 & 0.8 \\
\hline Completed middle school & 2 & 1.5 \\
\hline Some high school & 21 & 15.9 \\
\hline Graduated high school & 43 & 32.6 \\
\hline GED & 17 & 12.9 \\
\hline Some college / technical school & 32 & 24.2 \\
\hline Completed college / technical & 14 & 10.6 \\
\hline school & 1 & 0.8 \\
\hline $\begin{array}{l}\text { Some graduate school } \\
\text { Completed graduate school }\end{array}$ & 1 & 0.8 \\
\hline Living Arrangements & 9 & 6.8 \\
\hline Homeless, live with family or friend & 46 & 34.8 \\
\hline Rent & 66 & 50.0 \\
\hline Own home & 11 & 8.3 \\
\hline Doubled up with family or friend & & \\
\hline
\end{tabular}

The demographic make-up of the sample was compared to data from the city, collected from U.S. Census data from 2008. In the study group there were higher rates of those not completing high school, having less college attendance, and fewer people who owned their own home compared to the city. 
The majority of participants were married or had a significant other (44.7\%), which compared to the city at $42.4 \%$. Twenty seven percent of the participants were single, compared to the city at $27.6 \%$. Divorced and separated subjects were at $25 \%$ in the study group compared to $30 \%$ in the city where the sample was drawn.

The majority of the participants (45\%) have either received a high school diploma or earned a GED. There is not a city comparison for GED. However, those with less than a high school diploma included $18 \%$ of the study sample, compared to the city which is at $13.9 \%$. Study participants with a minimum of some college education were at $36 \%$, which is a lesser finding than the overall city of $49 \%$.

Place of residence is also compared to the city data. In the study population $34.8 \%$ of participants rented their home or apartment compared to $36.6 \%$ of the city. A difference was noted in home owners with $50 \%$ of the participants claiming they owned their home, which was lower than findings for the city at $63 \%$.

\section{Research Question Two}

How is health status described in working women who are poor and uninsured?

The following indicators of health status were examined: needing medical care, having a usual health care provider, having a chronic illness, smoking, obtaining a PAP smear, rating of general health status, and rating of life satisfaction. After examination of the initial findings of the study two variable categories were collapsed to analyze the research question. The variable 
measuring general health status originally included five categories and was collapsed into two categories to include excellent or very good and good, fair, or poor. Life satisfaction was measured with four categories and was collapsed into two categories to include satisfied or dissatisfied. The variables of both general health status and life satisfaction were collapsed to ensure the assumptions for Chi-square testing were met and to facilitate statistical testing. This collapse enabled variables to be reported in the same way as those in the West Virginia Behavioral Risk Factor Surveillance questionnaires for the state of West Virginia in the years of 2007 and 2009, which were used in comparison with the study group. Table 3 presents an overview of the health status indicator findings showing the collapsed variables for the study sample and for the state. 
Table 3: Overview of Health Indicators

\begin{tabular}{|c|c|c|c|}
\hline & & Sample & WVBRFSS \\
\hline $\begin{array}{l}\text { Health Indicator } \\
n=132\end{array}$ & Frequency & Percentage & Percentage \\
\hline $\begin{array}{l}\text { Needed medical care, but could not } \\
\text { afford }\end{array}$ & & & \\
\hline (n) & $\begin{array}{r}104 \\
26\end{array}$ & $\begin{array}{l}78.8 \\
19.7\end{array}$ & $20.1 \ddagger$ \\
\hline Have a regular health care provider & & & \\
\hline $\begin{array}{l}\text { Yes } \\
\text { No }\end{array}$ & $\begin{array}{l}72 \\
57\end{array}$ & $\begin{array}{l}54.5 \\
43.2\end{array}$ & $15.6 \ddagger$ \\
\hline Hypertension & & & \\
\hline $\begin{array}{l}\text { Yes } \\
\text { No }\end{array}$ & $\begin{array}{l}61 \\
68\end{array}$ & $\begin{array}{l}46.2 \\
51.5\end{array}$ & $31.9^{*}$ \\
\hline Diabetes & & & \\
\hline $\begin{array}{l}\text { Yes } \\
\text { No }\end{array}$ & $\begin{array}{r}25 \\
104\end{array}$ & $\begin{array}{l}18.9 \\
78.8\end{array}$ & $11.5 \ddagger$ \\
\hline Smoking & & & \\
\hline $\begin{array}{l}\text { Yes } \\
\text { No }\end{array}$ & $\begin{array}{l}59 \\
71\end{array}$ & $\begin{array}{l}44.7 \\
53.8\end{array}$ & $24.6 \ddagger$ \\
\hline PAP test in last three years & & & \\
\hline $\begin{array}{l}\text { Yes } \\
\text { No }\end{array}$ & $\begin{array}{l}98 \\
32\end{array}$ & $\begin{array}{l}74.2 \\
24.2\end{array}$ & $17.4^{*}$ \\
\hline General Health Status & & & \\
\hline $\begin{array}{l}\text { Excellent / Very good } \\
\text { Good / Fair / Poor }\end{array}$ & $\begin{array}{r}26 \\
104\end{array}$ & $\begin{array}{l}19.7 \\
78.8\end{array}$ & $24.6 \ddagger$ \\
\hline $\begin{array}{l}\text { Life Satisfaction } \\
\text { Very Satisfied / Satisfied } \\
\text { Dissatisfied / Very Dissatisfied }\end{array}$ & $\begin{array}{r}102 \\
28\end{array}$ & $\begin{array}{l}77.3 \\
21.2\end{array}$ & $91.4^{*}$ \\
\hline
\end{tabular}

*WVBRFSS $2007 \quad$ ‡WVBRFSS 2009

Demographic variables and health indicators

Categorical variables. Chi-square analysis was completed with the categorical demographic variables of marital status, education, residence, and insurance status for each health indicator. Significance was noted with the variables of hypertension and education $(p=.003)$, hypertension and insurance 
( $p=.037)$, PAP screening and education $(p=.010)$, and PAP screening and insurance $(p=.016)$. Those with more education were more likely to report less occurrences of hypertension and were more likely to have PAP screening. Concerning health insurance, those who held health insurance in the past were more likely to report less occurrences of hypertension and more likely to have PAP screening (Table 4).

Table 4: Relationship of Significant Health Status Indicators and Demographics

\begin{tabular}{|c|c|c|c|c|c|c|c|c|}
\hline \multirow[t]{2}{*}{$n=130$} & \multicolumn{4}{|c|}{ Hypertension } & \multicolumn{4}{|c|}{ PAP in Last 3 Yrs } \\
\hline & Yes & No & $\begin{array}{r}\text { Chi } \\
\text { Square }\end{array}$ & $p$ & Yes & No & $\begin{array}{r}\text { Chi } \\
\text { Square }\end{array}$ & $p$ \\
\hline Insurance & & & 6.58 & .037 & & & 5.65 & .016 \\
\hline Yes & 33 & 50 & & & 68 & 15 & & \\
\hline No & 27 & 18 & & & 29 & 17 & & \\
\hline Education & & & 1.47 & .030 & & & 13.23 & .010 \\
\hline No High School & 18 & 6 & & & 16 & 8 & & \\
\hline High School / GED & 28 & 30 & & & 38 & 21 & & \\
\hline College & 15 & 32 & & & 44 & 3 & & \\
\hline
\end{tabular}

Continuous variables. Independent sample $t$-tests with continuous demographic variables were conducted for each dichotomous health indicator. The continuous demographic variables included the number of individuals living in the home and the study participant's age (Table 5). Significance was noted with the variable of age and hypertension $(p=.001)$. Concerning age, those who were older were more likely to experience hypertension. Significance was also 
noted with the number living in the home and life satisfaction $(p=.005)$. Those with more individuals living in the home were more likely to rate their life satisfaction as either very satisfied or satisfied (Table 6).

Table 5: $t$-tests for Number Living in the Home and Age by Health Indicator

\begin{tabular}{l|rcrr}
\hline$n=130$ & \multicolumn{2}{|c}{ Number in Home } & \multicolumn{2}{c}{ Age } \\
\hline Needed Medical Care & \multicolumn{1}{|c}{$t$} & $p$ & .1 .62 & .113 \\
Health Care Provider & .998 & .320 & -1.134 & .259 \\
Hypertension & -1.071 & .286 & 3.92 & $.000^{*}$ \\
Diabetes & 1.46 & .155 & .852 & .400 \\
Smoking & .331 & .742 & -.264 & .792 \\
Pap in 3 Years & -.996 & .324 & .975 & .334 \\
General Health Status & -.805 & .426 & -.100 & .921 \\
Life Satisfaction & 2.84 & $.005^{*}$ & -1.364 & .179 \\
\hline${ }^{*} p<.05$ & & & &
\end{tabular}


Table 6: Significant $t$-tests for Number Living in the Home and Age by Health Indicator

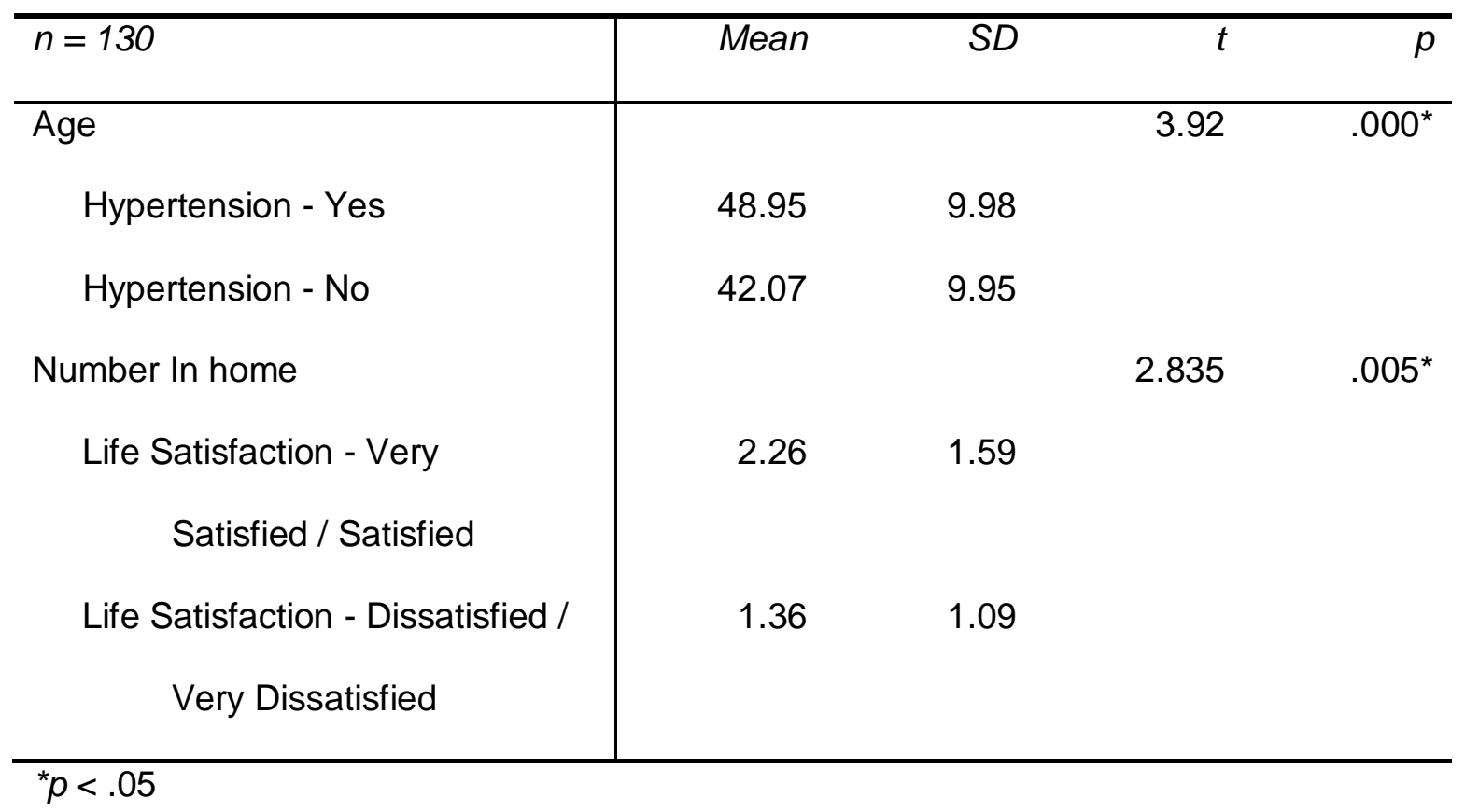

\section{Research Question Three}

How is $L R$ described in working women who are poor and uninsured?

In this study 121 (91\%) of the participants completed the SCS, measuring LR. The mean score was 19.5 with a standard deviation of 22.25. The median score was 22 with scores ranging from -59 to 71 . The possible range of scores of the instrument is -108 to 108 (Rosenbaum, 1990). A mean of 19.5 compared to the median of 22 indicates the data are skewed to the left (Figure 2). 
Figure 2: Histogram Representing Learned Resourcefulness Scores

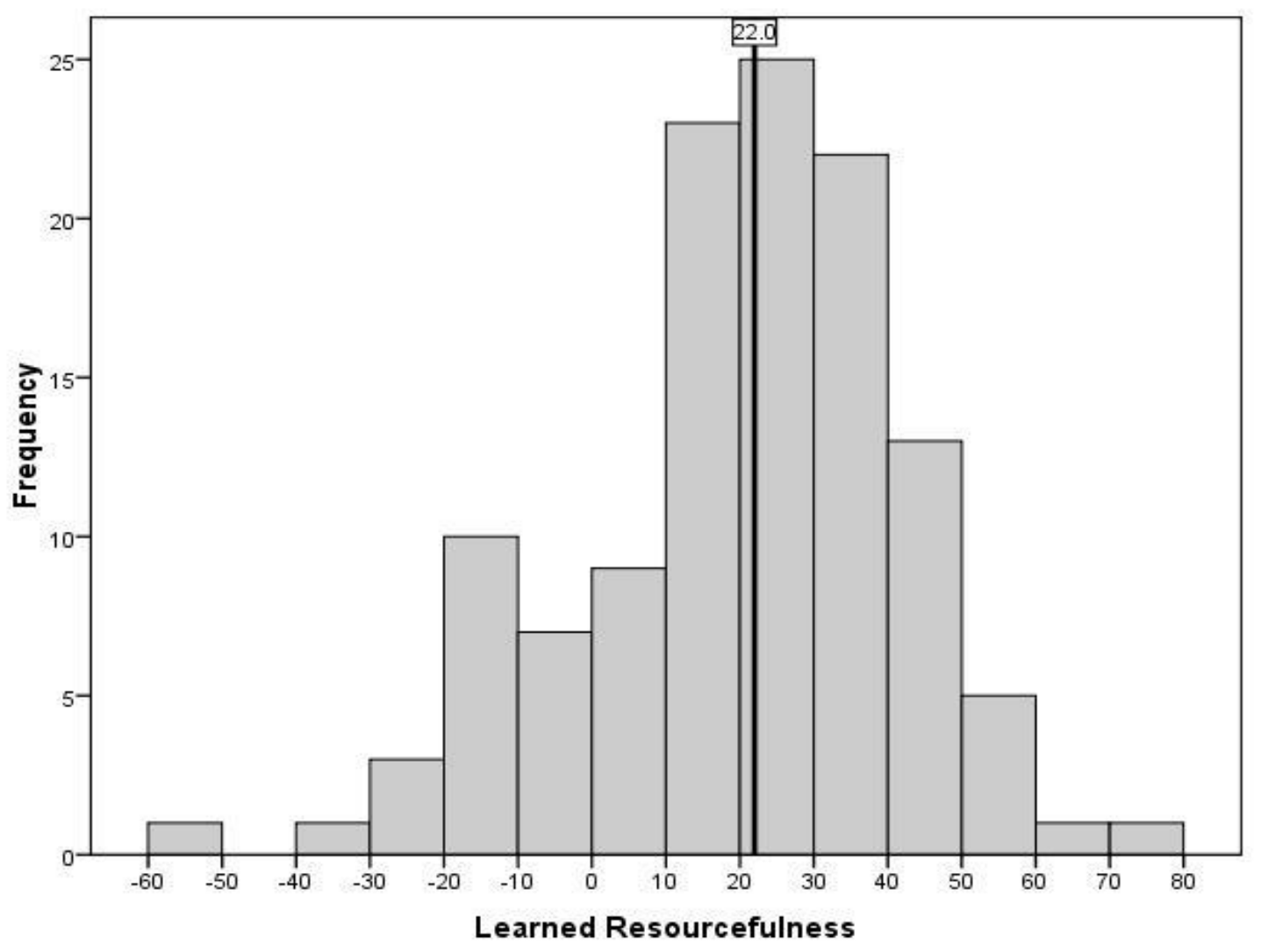

As part of the description of LR in working women who are poor and uninsured, analyses were completed for differences in LR by demographic variables. ANOVA was utilized with categorical demographic variables with more than two levels and included marital status, education, and residence (Table 7). No statistical significance was found between LR and demographic variables.

An independent $t$-test was completed with the variables of LR and health insurance. Findings were not significant $(p=.189)$, indicating there was no statistically significant difference in LR and health insurance. Differences in LR and health indicators were analyzed using independent $t$-tests. No statistically significant differences in LR for each health indicator were found. 
Table 7: Analysis of Variance of LR and Demographic Variables

\begin{tabular}{l|rcrr}
\hline$n=121$ & Mean & $S D$ & $F$ & $p$ \\
\hline Marital status & & & .212 & .809 \\
Single & 17.88 & 26.28 & & \\
Divorced, Separated, Widowed & 18.85 & 22.11 & & \\
$\quad$ Married, Significant other & 20.93 & 19.81 & & \\
Education & & & 2.68 & .073 \\
No high school & 18.77 & 21.10 & & \\
High school / GED & 15.11 & 24.69 & & \\
College & 25.36 & 18.40 & & \\
Residence & & & .640 & .529 \\
Homeless & 16.26 & 24.49 & & \\
Rent & 17.73 & 22.39 & & \\
Own home & 21.77 & 21.56 & & \\
\hline
\end{tabular}

Lastly, LR was correlated with age and number of individuals in the household. The relationship between LR and age was calculated using the Pearson product-moment correlation coefficient. There was no statistically significant correlation between LR and age $(n=121, r=.083, p=.367)$. The relationship between LR and number of individuals in the household was investigated with the same procedure. No statistically significant correlation was found $(n=121, r=.100, p=.274)$ between LR and the number of individuals living in the home. 


\section{Research Question Four}

How is WB described in working women who are poor and uninsured?

In this study $127(96.2 \%)$ of the participants completed the IWB. The mean score was 9.33, median score was 9.6, standard deviation was 2.27, and scores ranged between 3.6 and 14.23. The possible range of the scores of the instrument is 2.1 to 14.7 (Campbell, Converse, and Rogers, 1976).

As part of the description of WB in working women who are poor and uninsured analyses were completed looking for differences in WB by demographic variables. ANOVA was utilized with categorical demographic variables with more than two levels and included marital status, education, and residence. Statistical significance was noted in two areas: marital status ( $p=$ $.041)$ and education $(p=.028)$. Subjects were divided into three groups concerning marital status. The mean score for those married or with a significant other was significantly different from those single $(p=.404)$ or those who are divorced or widowed $(p=.497)$. Those who are married report a higher level of WB than those who are single and those who are divorced or widowed. Educational status was also divided into three groups. The mean score for those with less than a high school education was significantly different from those who completed high school or earned a GED $(p=.036)$ or those with at lease some college $(p=.038)$. Those who have less than a high school education report a higher level of WB than those who have completed high school or obtained a GED, or have gone to college (Table 8). 
Table 8: Analysis of Variance of Well-being and Demographic Variables

\begin{tabular}{l|cccr}
\hline$n=127$ & Mean & $S D$ & $F$ & $p$ \\
\hline Marital status & & & 3.29 & $.041^{*}$ \\
$\quad$ Single & 9.21 & 2.05 & & \\
Divorced, separated, widowed & 8.61 & 2.58 & & \\
$\quad$ Married, SO & 9.83 & 2.11 & & \\
Education & & & 3.69 & $.028^{*}$ \\
No high school & 10.44 & 2.42 & & \\
High school / GED & 9.09 & 2.29 & & \\
$\quad$ College & 9.05 & 2.03 & & \\
Residence & & & 2.13 & .123 \\
Homeless & 8.59 & 2.71 & & \\
Rent & 9.13 & 1.92 & & \\
Own home & 9.70 & 2.30 & & \\
\hline
\end{tabular}

${ }^{*} p<.05$

WB was examined with the demographic variable of health insurance using an independent $t$-test. No statistical significance was found $(p=.447)$ indicating there were no differences in WB and health insurance. Differences in WB and health indicators were examined using independent $t$-tests. There was statistical significance with WB and life satisfaction $(p=.001)$.Those with a higher level of life satisfaction rated their sense of WB higher (Table 9). 
Table 9: $t$-tests of Well-being by Health Indicators.

\begin{tabular}{|c|c|c|c|c|}
\hline$n=127$ & Mean & $S D$ & $\bar{t}$ & $\bar{p}$ \\
\hline $\begin{array}{l}\text { Medical Care } \\
\text { Yes } \\
\text { No }\end{array}$ & $\begin{array}{r}9.17 \\
10.12\end{array}$ & $\begin{array}{l}2.35 \\
1.76\end{array}$ & -1.87 & .064 \\
\hline $\begin{array}{l}\text { Health Care Provider } \\
\text { Yes } \\
\text { No }\end{array}$ & $\begin{array}{l}9.18 \\
9.58\end{array}$ & $\begin{array}{l}2.07 \\
2.51\end{array}$ & -.968 & .335 \\
\hline $\begin{array}{l}\text { Hypertension } \\
\text { Yes } \\
\text { No }\end{array}$ & $\begin{array}{l}9.27 \\
9.38\end{array}$ & $\begin{array}{l}2.59 \\
1.96\end{array}$ & -.285 & .776 \\
\hline $\begin{array}{l}\text { Diabetes } \\
\text { Yes } \\
\text { No }\end{array}$ & $\begin{array}{l}8.77 \\
9.45\end{array}$ & $\begin{array}{l}2.38 \\
2.24\end{array}$ & -1.31 & .191 \\
\hline $\begin{array}{l}\text { Smoking } \\
\text { Yes } \\
\text { No }\end{array}$ & $\begin{array}{l}9.00 \\
9.64\end{array}$ & $\begin{array}{l}2.45 \\
2.09\end{array}$ & -1.59 & .114 \\
\hline $\begin{array}{l}\text { Pap in } 3 \text { Years } \\
\text { Yes } \\
\text { No }\end{array}$ & $\begin{array}{l}9.44 \\
9.05\end{array}$ & $\begin{array}{l}2.28 \\
2.27\end{array}$ & .825 & .411 \\
\hline $\begin{array}{l}\text { General Health Status } \\
\text { Excellent, Very good } \\
\text { Good, Fair, Poor }\end{array}$ & $\begin{array}{l}9.75 \\
9.25\end{array}$ & $\begin{array}{l}2.32 \\
2.26\end{array}$ & .989 & .325 \\
\hline $\begin{array}{l}\text { Life Satisfaction } \\
\text { Very satisfied, Satisfied } \\
\text { Dissatisfied, Very Dissat }\end{array}$ & $\begin{array}{r}10.02 \\
6.98\end{array}$ & $\begin{array}{l}1.86 \\
2.02\end{array}$ & 7.49 & $.000^{*}$ \\
\hline
\end{tabular}

The relationship between WB and age, and between WB and the number of people living in the home was analyzed using Pearson product-moment correlation coefficient. There was a small, positive correlation between WB and number living in the home $(\mathrm{n}=127, r=.182, p=.040)$ with higher levels of WB associated with more individuals living in the home. There was no statistically significant correlation between WB and age $(\mathrm{n}=132, r=.089, p=.331)$. 


\section{Research Question Five}

What is the relationship between $L R$ and WB?

The relationship between LR and WB was analyzed with the Pearson product-moment correlation. There was a medium, positive correlation between the two variables $(\mathrm{n}=121, r=.395, p=.001)$ with higher levels of $\mathrm{LR}$ with increasing levels of WB. This finding is congruent with Rosenbaum (1990), who notes a higher level of LR is demonstrated by the individual taking action to promote WB.

\section{Research Question Six}

How do LR and significant demographic variables work together to predict WB?

Multiple linear regression with WB as the response variable in a model with LR and demographic variables as predictor variables was used. To investigate the final model both forward and backward regression was performed. With forward regression the independent variable that had the highest correlation with the dependent variable was entered into the analysis first. The next variable to be entered into the analysis was the independent variable that contributed most to the prediction of the dependent variable with a significance level less than 0.05 . The effect was measured by the increase in $R^{2}$ due to the second variable. This process continued until the predictor variables stopped making significant contributions (Mertler \& Vannatta, 2005). Backward regression first computed an equation with all predictors included. Then, a significance test was conducted for every predictor. If the significance value was less than 0.10 the predictor was removed and a new equation with the remaining variables was 
computed. This process continued until only significant predictors remained in the equation (Mertler \& Vannatta, 2005).

Forward multiple regression was conducted to determine which independent variables (LR, education, number in the home, age, residence, and marital status) were the significant predictors of WB in the final model.

Regression results indicated an overall model of three predictors (LR, education, and the number living in the home) significantly predict WB, $R^{2}=.276, p=.017$. This model accounted for $27.6 \%$ of the variance in WB. Collinearity was assessed. Tolerance and variance inflation factor statistics suggested this model did not have a collinearity problem. These results are consistent with the final model. The standard regression coefficients demonstrated the $L R$ variable contributed most to the prediction of WB $(\beta=0.420)$, followed by level of education ( $\beta=-0.294)$, and number living in the home $(\beta=0.248)$ (Table 10). Thus women with higher LR, less education, and more people living in the home were more likely to have higher levels of WB. 
Table 10: Prediction of Well-being with Learned Resourcefulness and Significant Demographic Variables

\begin{tabular}{l|rrrrr}
\hline Model & \multicolumn{1}{|c}{$\begin{array}{c}\text { Unstandardized } \\
\text { Coefficients }\end{array}$} & $\begin{array}{c}\text { Standardized } \\
\text { Coefficients }\end{array}$ & $t$ & Sig \\
$R^{2}=.276$ & B & Std. Error & Beta & & \\
\hline & 9.162 & 0.806 & & 11.366 & $.000^{*}$ \\
Constant & 0.043 & 0.008 & 0.420 & 5.151 & $.000^{*}$ \\
LR & -0.929 & 0.257 & -0.294 & -3.620 & $.000^{*}$ \\
Education & 0.601 & 0.248 & 0.248 & 2.423 & $.017^{*}$ \\
Home & & & & &
\end{tabular}

\section{Research Question Seven}

How do LR and significant demographic variables work together to predict perception of general health?

Multiple regression with general health perception as the response variable was measured on a scale of one through five, in a model with LR and demographic variables as predictor variables. In past analysis general health perception was collapsed and considered dichotomous (excellent/very good or good/fair/poor), but for this analysis it was expanded and treated as continuous. Neither LR nor demographic variables were significant $(p=.340)$ in contributing to a model predicting general health perception (Table 11). 
Table 11: Prediction of General Perception of Health with Learned Resourcefulness and Significant Demographic Variables

\begin{tabular}{|c|c|c|c|c|c|}
\hline Model & \multicolumn{2}{|c|}{$\begin{array}{r}\text { Unstandardized } \\
\text { Coefficients }\end{array}$} & $\begin{array}{r}\text { Standardized } \\
\text { Coefficients }\end{array}$ & $\bar{t}$ & Sig \\
\hline & $B$ & Std. Error & Beta & & \\
\hline Constant & 2.095 & .571 & & 3.67 & .000 \\
\hline SCS Total & -.001 & .004 & -.017 & -.175 & .861 \\
\hline Education & -.079 & .129 & -.059 & -.613 & .541 \\
\hline Home & .144 & .129 & 1.09 & 1.12 & .266 \\
\hline Marital & .009 & .135 & .007 & .066 & .947 \\
\hline Age & .014 & .011 & .148 & 1.29 & .202 \\
\hline \# in Home & .108 & .063 & .172 & 0.72 & .088 \\
\hline
\end{tabular}

\section{Summary of Findings}

There were three significant findings in this study or working women who were poor and uninsured. Following is a summary of the findings. Participants in this study scored lower on health status indicators than the comparison population from the state. This participant group indicated they were not receiving health care as frequently, had a higher incidence of chronic health problems, and worked less at health promoting behaviors. Their general health status was rated lower, along with a lower life satisfaction rating.

The sample of working, poor, uninsured women in this study scored a mean of 19.5 , a median of 22 , and a standard deviation of 22.5 on the SCS. The same sample scored a mean of 9.33 , median of 9.6 and standard deviation of 2.27 on the IWB. 
There was a statistically significant, positive relationship between LR and WB. As the level of WB increases LR increases, providing some validation to Rosenbaum's (1990) position that higher LR is demonstrated by an individual taking action to promote WB. LR, education, and number of persons living in the home together predicted $28 \%$ of the variance in WB. LR contributed the most to the prediction, followed by level of education and number living in the home. 


\section{Chapter 5: Discussion}

The purpose of this research study was to describe the interrelationships between LR, health status, and WB in working women who are poor and uninsured. This chapter offers an interpretation of significant findings with review of existing evidence. The discussion will be organized first by significant findings, strengths and limitations, and implications for nursing research and practice.

\section{Significant Findings}

Health Status in Working Women Who are Poor and Uninsured

Participants in this study differed in health status from the comparison group of women in the state. Participants identified times when they needed health care and yet could not afford the necessary health care. When care is provided at a free clinic patients are not obligated to pay for any services. However, costs may ensue in addition to care in terms of medical supplies, diet modifications, transportation to appointments, or lost work hours.

Furthermore, participants did not have someone they identified as their regular health care provider. Care in this clinic was administered by both paid and volunteer providers, resulting in the potential for fragmented care. Patients are not guaranteed to see the same provider at each visit and this may contribute to not having a usual person to identify as their health care provider.

Having insurance and increased education influenced the health status indicators of hypertension, obtaining a PAP smear, and smoking. Even though participants in this study had a higher incidence of hypertension than the state comparison group, those who held insurance in the past had lower rates of 
hypertension. It may be having had health insurance afforded access to health care to detect or prevent blood pressure problems (Deck, 2008). Routine care for hypertension includes lifestyle management, importance of exercise, and dietary modifications. In addition, the more education an individual has may positively affect how a person engages in hypertension management through prevention and the control of risk factors. In this study those who completed at least a high school education had lower rates of hypertension.

Insurance status and level of education affected the behaviors of obtaining a PAP smear and of smoking. Women who held health insurance in the past were more likely to obtain PAP screening. This may be attributed to the improved access insurance provides (Deck, 2008). Those with at least a high school education were more likely to obtain PAP screening. Participants in this study smoked more than their state comparison group. However, those who held health insurance and had at least a high school education smoked less than those who did not. Lower socioeconomic status is a risk factor for tobacco use (Hegewald \& Crapo, 2007). Janzon, Engstrom, Lindstrom, Bergland, Hedbland, and Janzon (2005) found a positive association between low socioeconomic status, less education, and unemployment in women who smoked.

Study participants rated both their general health status and life satisfaction lower than their state comparison group. Galambos (2006) contends health status in poor women is three times more likely to be reported as fair or poor. Contributing to this finding may be that poor, working women's usual source of care is the emergency room. They have no usual source of care, report 
not being able to fill a prescription due to cost, and often consider going without care because of the cost (Deck, 2008). Life satisfaction in low income and working poor women is compounded by competing stressors and tensions. They are vulnerable to family chaos, poor decision making, and the inability to plan beyond immediate needs. To achieve stability and some level of satisfaction women and their families need economic stability, safety, good health, and engagement in the larger community (Dyk, 2004). Those participants who had more persons living in the home with them had a higher rating of life satisfaction. This may be due to what Shipler (2004) describes as a network of caring and connectedness within a family and beyond that makes the world a less threatening place.

Learned Resourcefulness in Working Women Who are Poor and Uninsured

Women in this study achieved a somewhat lower LR median (22) and mean (19.5) score than noted in other studies. Rosenbaum's $(1980,1990)$ description of a normal population is a median score of 25. In studies of adults, Rosenbaum and Palmon (1984), Zauszniewski (1994a, 1996), and Kennett and Ackerman (1994) reported median scores ranging from 24-26 with study means ranging from 38.8 to 80.6 . These scores from prior studies included women attempting weight loss, adults with chronic illness, and adults with depression. The studies cited represent individuals faced with specific pressures and demands. Women attempting weight loss are self-motivated concerning working toward a personal goal. Chronic illness requires a person to learn to manage their illness in addition to routine daily life pressures and demands. Adults in the 
study with depression were learning health-seeking resources and measures of adaptive functioning. These skills would likely boost resourcefulness scores. Kennett, Morris, and Bangs (2006) reported highest SCS means (23.86) in those who have never smoked and the lowest means (10.57) in those who have relapsed with smoking. Carey, Carey, Carnrike, and Meisler (1990) report the highest study means (24.8) in those who drink infrequently or abstain from alcohol compared to moderate or heavy drinkers. These findings with drinking and smoking indicate those who have the ability to not engage have higher levels of resourcefulness, compared to those who give in to addictive behaviors. It may be that women in this study had lower median and mean scores because being poor and uninsured, along with the resulting pressures and demands, alter the use of cognitive strategies, problem solving skills, delay in gratification, and the belief in the ability to perform, thus hindering higher levels of resourcefulness.

Resourcefulness scores of college students were also reviewed in comparison to study findings. College students are goal directed, have adequate cognitive abilities, and are able to delay wants and desires to complete their degree requirements. Two studies of college students examined stress (Akgun \& Ciarrhochi, 2003; Ginter, West, \& Zarski, 2001). Study means ranged from 21 to 57. Both studies found that those with higher resourcefulness either perceived the stressor as less severe or were more resourceful and able to vary their methods of coping. McWhirter (1997) studied loneliness in college students. Findings were those with higher levels of LR were less lonely. These students 
may enter college either more adept at using the skills associated with LR or are able to learn them from modeling other successful classmates.

Rosenbaum (1990) stated the behaviors and skills of LR are learned, beginning at birth and learning continues throughout life. In this study age did not correlate significantly with LR. Rosenbaum (1990) contends LR over time is related to the self-control of behavior. Self-control involves challenges that produce intense physiological and emotional reactions that have adverse effects on LR. This sample of working, poor, uninsured women confronted challenges and stressors in their life that may contribute to an impedance of LR as the person aged.

\section{Learned Resourcefulness and Well-Being}

There was a positive, statistically significant relationship between LR and WB, with higher levels of LR with increasing levels of WB. Campbell, Converse, and Rodgers (1976) focus their description of WB as an expression of a cumulative, global satisfaction with specific domains of life. Modern society is dynamic and individuals are faced with demanding, changing, and challenging situations. These dynamic situations produce emotional and physiologic reactions that may affect their WB (Rosenbaum, 1990). Drawing on the individual tendencies of cognitive strategies, problem solving skills, delay of gratification, and belief in the ability to perform comprising LR may facilitate an individual in meeting dynamic challenges while preserving their overall sense of WB. Women in a study by Collins (2005) identify qualities of a good life that promotes their WB. These qualities bear similarities to the individual tendencies that are part of 
LR. Qualities identified include belief in the ability to perform by their level of selfesteem, courage, and management of the every day, in addition to any emergency that arises. The women identify stressors in their lives such as lack of income, poor housing, poor health, and not having enough to eat which, when overcome or managed successfully, may improve their cognitive abilities. The combination of loved ones, family, friends, and spirituality may improve problem solving skills by improving a network of support, thus with the indirect result of improving cognitive strategies. Dyk (2004) describes this extended family experience as a benefit to those who are poor.

LR, education, and number of persons living in the home predicted $28 \%$ of the variance in WB. Achieving higher levels of education reduces the incidence of being poor and those with more education have greater access to higher paying jobs (Monthly Labor Review, 2006). Higher paying jobs are associated with less economic stress, less barriers to health care, safer living environments, and better family and community arrangements (Dyk, 2004). Field (2009) presents a view that adult learning and level of education has a positive impact on WB. Learning and education may positively influence employability and earning and enable a more positive outlook on the future. The majority of participants in this study (45.5\%) had at least earned a high school diploma or GED. More people living in the home contributed to a higher level of WB. Dyk (2004) reports benefits poor families may have that promote strength. These benefits may stem from improved problem-solving skills, confidence to pull together, and having someone to depend upon when problems arise. Shipler 
(2005) suggests that those beyond the immediate family provide a safety net improving dimensions of life, reducing loneliness and increasing WB. Those who are married reported a higher level of WB than those who are single, divorced, or separated.

Three specific findings concerning WB emerged from the study. Wellbeing was not affected by having held health insurance. Having held health insurance in the past afforded opportunities for education and health screenings, thereby promoting wellness. Women in this study group have unrestricted access to the clinic and are not dependent on health insurance. WB was positively correlated with the number of persons living in the home. This study did not specifically determine who was included in the home, but findings from other studies provide insight into the support network and importance of kinship others may bring to the home. Higher levels of WB were noted in those with less than a high school education. This finding is contradictory in comparison to other findings noting more education leads to better paying jobs. Higher paying jobs are associated with less economic stress, less barriers to health care, safer living environments, and better family and community arrangements (Dyk, 2004). Findings in Relation to the Model of Learned Resourcefulness

The model constructed to guide this study was based on the work of Rosenbaum (1990). The insertion of the concepts of individual tendencies and the specific health consequences were included as part of the model. The model and research questions used in this study implied three relationships among the variables. First, it implies that LR is related to WB. The findings of this study 
support the implication. Secondly, it was implied that LR and demographic variables would predict WB. The findings of this study support the implication. $L R$, level of education, and number living in the home predicted $28 \%$ of the variance in WB. The third implication was that $L R$ and demographic variables would predict general health status. This implication was not supported by the findings of this study. The model as conceptually structured by this study was partially supported in the group of poor, uninsured working women.

There is potential for use of this model in nursing and with other disciplines. LR has been studied by researchers from at least four disciplines (nursing, psychology, education, and social work). The framework of the model supports measuring pertinent consequences that could be used in an interdisciplinary study. The model has the breadth and scope necessary to guide future research and practice.

\section{Study Strengths and Limitations}

The opportunity to collect data at a clinic that was dedicated to women who are poor and uninsured was a strength of the study. This focused setting provided a sample of women who met the criteria of being poor, uninsured, and working. The willingness of the clinic patients to participate in the study was an additional strength. In addition the SCS and IWB both had good estimates of reliability for this sample of poor, uninsured, working women.

Limitations included the uni-dimensional measure of LR and a convenience sample of volunteers. Measuring a multi-dimensional concept that includes cognitive strategies, problem solving skills, delay of gratification, and 
belief in ability to perform as one score presents a limitation of the instrument in its current form. Thus Zauszniewski (1997b) infers subscales are contained within the SCS promoting multi-dimensional use and the subscales are able to be used independently. Analysis of LR using subscales has not been identified in the literature. In addition the indicators chosen to measure health status were limited. Some were dichotomous and some categorical. Seeking a stronger measure of health that is reliable and valid is indicated.

This study involved a convenience sample of women who came into the clinic over a three week time span. Only one clinic was used. Those volunteering to participate may have been feeling more frustration or agitation with their situation, thus prompting the willingness to participate in a study. Patients with less frustration in their lives may be less interested in completing a survey.

Implications for Nursing Research

A replication of the study with another sample in another region of poor, uninsured, working women is warranted to give validation to the current findings. A study measuring LR in men is also worthy of consideration. A qualitative study addressing questions on the individual tendencies such as: Talk to me about what you do to improve your situation; What specific things do you do when you are faced with pressures and demands; What at this time in your life do you have to put off; What do you do in your life that is working well and why? A directed content analysis to identify the themes related to each of the tendencies could be the method used in this study. A qualitative study could lay the groundwork for 
instrument development, possibly advancing the dimensions of the current capacity.

The finding of WB increasing with a higher number of individuals living in the home prompts the question investigating "who" is in the home that may contribute to this finding. Future research could include demographic questions asking not only the number in the home, but also who the members are and the ages.

The current economic times have had an impact in almost every community with unemployment being at new highs. Communities, along with state and local governments, are strapped and social resources in great demand. Most people obtain health insurance through their employer (Kaiser Family Foundation, 2009a) and women are less likely to be insured through their own job and more likely to have dependent coverage (Kaiser Family Foundation, 2009b). The full impact of the current recession has not yet been felt and increases in unemployment will lead to further loss of health insurance and the rate of those uninsured is projected to increase (Kaiser Family Foundation, 2009a). These unfortunate happenings provide a timely need for more research into the unique situations and problems for those who are working, yet poor and uninsured.

\section{Implications for Nursing Practice}

There are three major implications stemming from this study. First, advanced practice nurses are responsible for providing care and directing health promoting strategies in their patients. These health promoting strategies may 
positively impact health, thus affecting the patient's level of LR. Dedicating advanced practice nurses (APN) to provide care for groups of patients so that a patient would receive care from one or two consistent nurse practitioners would enable the patient to identify with a person throughout the time they are receiving care and lead to better health outcomes. Hartley (2002) states patients receiving care by regular providers of care had sustained relationships that allowed for communication of health concerns and improved primary care outcomes. The APN who is responsible for a group of patients will be able to know the patients on a more intimate basis. This improved knowledge allows the APN to identify strengths and limitations the patient may have that promotes or hinders LR. The APN can begin to work with the patient to reinforce the strengths already present and to modify limitations, working to reduce the limitation or manipulate it into a strength.

Secondly, advance practice nurses who serve groups of poor, uninsured, working women who are low in LR have the opportunity to teach the skills promoting resourcefulness. Zauszniewski (1997), Zauszniewski and Chung (2001), and Zauszniewski, Eggenschwiler, Preechawong, Roberts, and Morris (2006) all report success in teaching resourcefulness skills to the elderly and women with diabetes. The teaching and reinforcement of resourcefulness skills include coping strategies, problem solving, positive self-talk, priority setting, and decision making skills (Zauszniewski, 1997). Teaching these skills of LR may help to promote a healthy, productive life-style and improved WB (Zauszniewski, 1997). 
Lastly, assessing for level of LR, education, and the number of persons living in the home may provide an indicator of WB based on the findings of this study. These are elements of a patient's social history that currently receive little attention. Taking the time to inquire about these aspects of WB may lead to the recognition of impingements on LR. Impingements can be further targeted for areas of improvement, leading to interventions the APN may employ with the patient. Interventions that reduce impingements and promote both WB and LR may have a positive impact on a person's health.

Conclusion

This study focused on the interrelationships between LR, health status, and well-being. Findings from the study offer a contribution to the knowledge base of nursing by relating LR to concepts of health status and well being in working women who are poor and uninsured. A gap in the literature was addressed through the study of LR with working women who are poor and uninsured. These women had lower levels of LR when compared to other groups reported in the literature. Implications stemming from the findings of this study for advanced practice nursing are significant. Women who are working, yet poor and uninsured come to the APN with unique situations that call for a consistent relationship over time to address their complex needs and concerns. In this relationship there is the potential to maximize LR skills influencing health consequences. 


\section{References}

Aikens, J.E., Wallander, J.L., Bell, D.S.H., \& Cole, J.A. (1992). Daily stress variability, learned resourcefulness, regimen adherence, and metabolic control in Type I diabetes mellitus: Evaluation of a path model. Journal of Consulting and Clinical Psychology, 60, 113-118.

Akgun, S. (2004). The effects of situation and learned resourcefulness on coping responses. Social Behavior and Personality, 32, 441-448.

Akgun, S., \& Ciarrochi, J. (2003). Learned resourcefulness moderates the relationship between academic stress and academic performance. Educational Psychology, 23, 287-294.

Baker, D.W., Feinglass, J., Durazo-Arvizu, R., Witt, W.P., Sudano, J.J, \& Thompson, J.A. (2006). Changes in health for the uninsured after reaching age-eligibility for Medicare. Journal of General Internal Medicine, 21, 1144-1149.

Braden, C.J. (1990). A test of the Self-Help model: Learned response to chronic illness experience. Nursing Research, 39, 42-47.

Beery, T.A., Baas, L.S., Fowler, C., \& Allen, G. (2002). Spirituality in persons with heart failure. Journal of Holistic Nursing, 20, 5-25.

Bekhet, A.K., Zauszniewski, J.A., \& Wykle, M.L. (2007). Milieu change and relocation adjustment in elders. Western Journal of Nursing Research, 30, 113-129.

Boonpongmanee, C., Zauszniewski, J.A., \& Morris, D.L. (2003). Resourcefulness and self care in pregnant women with HIV. Western Journal of Nursing Research, 25, 75-92.

Campbell, A., Converse, P.E., \& Rodgers, W.L. (1976). The quality of American life. Perceptions, evaluations, and satisfactions. New York: Russell Sage Foundation.

Carey, M.P., Carey, K.B., Carnrike, C.L.M., \& Meisler, A.W. (1990). Learned resourcefulness, drinking, and smoking in young adults. Journal of Psychology, 124, 391-395.

Centers for Disease Control and Prevention (2010). Behavioral Risk Factor Surveillance System [On-line]. Available: http://www.cdc.gov/brfss/about.htm 
Chang, H., Zauszniewski, J. A., Heinzer, M.M., Musil. C.M., \& Tsai, W. (2007). Adaptive functioning and depressive symptoms in school-aged children. Journal of Advanced Nursing, 60, 502-512.

Cheng, T. (2005). The impact of welfare reform, health, and insurance status on welfare recipients health care access. Journal of Health Care for the Poor and Underserved, 16, 588-599.

Collins, S.B. (2005). An understanding of poverty from those who are poor. Action Research, 3, 9-31.

Deck, K. (2008). A snapshot of the uninsured: A commentary. Women's Health Care, 7, 51-53.

Dirksen, S.R. (1990). Theoretical modeling to predict subjective well-being. Western Journal of Nursing Research, 12, 629-643.

Dodson, L. (2007). Wage-poor mothers and moral economy. Social Politics, 14, 258-280.

Dyk, P.H. (2004). Complexity of family life among the low-income and working poor: Introduction to the special issue. Family Relations, 53, 122-126.

Economic Research Initiative on the Uninsured. (n.d.). Fast facts. Retrieved Feb. 12, 2008 from http://eriu.sph.umich.edu/fastfacts/consider.html

Ford, E.S., Will, J.C., DeProst Ford, M.A., \& Mokdad, A.H. (1998). Health insurance status and cardiovascular risk disease among 50-64 year old U.S. women: Findings from the third National Health and Nutrition Examination Survey. Journal of Women's Health, 7, 997-1006.

Fowler, C., \& Baas, L.S. (2006). Illness representations in patients with chronic kidney disease on maintenance hemodialysis. Nephrology Nursing Journal, 33, 173-187.

Galambos, C.M. (2006). Health care coverage for poor women: Dwindling support. Health \& Social Work, 31, 3-6.

Ginter, G.G., West, J.D., \& Zarski, J.J. (2001). Learned resourcefulness and coping with stress. Journal of Psychology, 123, 295-304.

Hartley, L. A. (2002). Examination of primary care characteristics in a communitybased clinic. Journal of Nursing Scholarship, 34, 377-382.

Hegewald, M. \& Crapo, R. (2007). Socioeconomic status and lung function. Chest, 132, 1608-1641. 
Hoffman, C.B. (2007). Simple truths about America's uninsured. American Journal of Nursing, 107, 40-47.

Holahan, J., \& Cook, A. (2009). Changes in health insurance coverage 20072008. Early impact of the recession. (KFF Publication No. 8004).

Holahan, J., \& Wang, M. (2004). Changes in health insurance coverage during the economic downturn: 2000-2002. Health Affairs, 31-42.

Huttlinger, K., Schaller-Ayers, J., \& Lawson, T. (2004). Health care in Appalachia: A population based approach. Public Health Nurse, 21, 103-110.

Janzon, E., Engstrom, G., Lindstrom, M., Berglund, G., Hedblad, B., \& Janzon, L. (2005). Who are the "quitters?" A cross-sectional study of circumstances associated with women giving up smoking. Scandinavian Journal of Public Health, 33, 175-182.

Johnson, K. (2006). Public finance policy strategies to increase access to preconception care. Maternal Child Health Journal, 10, 85-91.

Johnson, M.O. (2001). Meeting health care needs of a vulnerable population: Perceived barriers. Journal of Community Health Nursing, 18, 35-42.

Kaiser Family Foundation. (2006). Who are the uninsured? A consistent profile across national surveys (K.F.F. Publication No. 7553). Washington, DC: Author.

Kaiser Family Foundation. (2007). The uninsured: A primer. Washington, DC: Author.

Kaiser Family Foundation. (2009a). The Uninsured and the difference health insurance makes. (K.F.F. Publication No. 1420-11). Washington, DC: Author.

Kaiser Family Foundation. (2009b). Women's health insurance coverage. (K.F.F. Publication No.6000-08) Washington, DC: Author.

Kennett, D.J., \& Ackerman, M. (1995). Importance of learned resourcefulness to weight loss and early success during maintenance: Preliminary evidence. Patient Education and Counseling, 25, 197-203.

Kennett, D.J., Morris, E., \& Bangs, A.M. (2006). Learned resourcefulness and smoking cessation revisited. Patient Education and Counseling, 60, 206-211. 
Koziol-McLain, J., Price, D.W., Weiss, B., Quinn, A.A., \& Honigman, B. (2000). Seeking care for non urgent medical conditions in the emergency department: Through the eyes of the patient. Journal of Emergency Nursing, 26, 554-563.

Labor Month In Review. (2003, July). Monthly Labor Review, 126, 2.

Labor Month In Review. (2006, July). Monthly Labor Review, 129, 2.

Leight, S. (2003). The application of a vulnerable population conceptual model to rural health care. Public Health Nursing, 20, 440-448.

Luce, S., \& Brenner, M. (2006). Women and class: What has happened in forty years? Monthly Review, 58, 80-93.

McWhirter, B.T. (1997). Loneliness, learned resourcefulness, and self-esteem in college students. Journal of Counseling and Development, 75, 460-469.

Mertler, C. R., \& Vannatta, R. A. (2005). Advanced and Multivariate Statistical Methods $\left(3^{\text {rd }}\right.$ ed.). Glendale, CA: Pyrczak Publishing.

Mundinger, M.O., Thomas, E., Smolowitz, J., \& Honig, J. (2004). Essential health care: Affordable for all? Nursing Economics, 22, 239-244

Mundt, M. (1998). Exploring the meaning of "underserved:" A call to action. Nursing Forum, 33, 5-10.

Nadkarni, N. (2004). The double whammy of chronic illness in underserved populations: Can we afford not to care? Medscape Public Health \& Prevention, 2.

National Literacy Trust. (2008). SMOGGING - how to test the readability of text (2008). National Literacy Trust [On-line]. Available: http://www.literacytrust.org

Newman, K. (1996). Working poor, working hard. The Nation, 1996 July, 20-23.

Orne, R. M., Fishman, S. J., Manka, M., \& Pagnozzi, M. E. (2000). Living on the edge: A phenomenological study of medically uninsured working Americans. Research in Nursing \& Health 23, 204-212.

Pedro, L.W. (2001). Quality of life for long-term survivors of cancer. Cancer Nursing, 24, 1, 1-11.

Picot, S.J., Zauszniewski, J.A., \& Delgado, C. (1997). Cardiovascular responses of African American female caregivers. Journal of National Black Nurses' Association, 9, 3-21. 
Preechawong, S., Zauszniewski, J.A., Heinzer, M.M.V., Musil, C.M., Kercsmar, C., \& Aswinanonh, R. (2007). Relationship of family functioning, selfesteem, and resourceful coping of Thai adolescents with asthma. Issues in Mental Health Nursing, 28, 21-36.

Potter, M.L., \& Zauszniewski, J.A. (2000). Spirituality, resourcefulness, and arthritis impact on health perception of elders with rheumatoid arthritis. Journal of Holistic Nursing, 184, 311-331.

Redden, E. M., Tucker, R. K., \& Young, L. (1983). Psychometric properties of the Rosenbaum schedule for assessing self-control. The Psychological Record, 33, 77-86.

Reed, P.G. (1987). Spirituality and well-being in terminally ill hospitalized adults. Research in Nursing and Health, 10, 335-344.

Richards, P. S. (1985). Construct validation of the self-control schedule. Journal of Research in Personality, 19, 208-218.

Rosenbaum, M. (1980). A schedule for assessing self-control behaviors: Preliminary findings. Behavior Therapy, 11, 109-121.

Rosenbaum, M. (1988). Learned resourcefulness, stress and self-regulation. In S. Fisher \& J. Reason (Eds.), Handbook of life stress, cognition, and health (pp. 483-496). New York: Wiley \& Sons.

Rosenbaum, M. (1990). Learned resourcefulness: On coping skills, self-control, and adaptive behavior. New York: Springer.

Rosenbaum, M., \& Ben-Ari, K. (1985). Learned helplessness and learned resourcefulness: Effects of noncontingent success and failure on Individuals in self-control skills. Journal of Personality and Social Psychology, 48, 198-215.

Rosenbaum, M., \& Jaffe, Y. (1983). Learned helplessness: The role of individual differences in learned resourcefulness. British Journal of Social Psychology,22, 215-225.

Rosenbaum, M., \& Palmon, N. (1984). Helplessness and resourcefulness in coping with epilepsy. Journal of Consulting and Clinical Psychology, 52, 244-253.

Rosswurm, M.A., Larrabee, J.H., \& Zhang, J. (2002). Training family caregivers of dependent elderly adults through on-site and telecommunications programs. Journal of Gerontological Nursing, 28 (7), 27-38. 
Seccombe, K., \& Amey, C. (1995). Playing by the rules and losing: Health insurance and the working poor. Journal of Health and Social Behavior, 36, 168-181.

Shipler, D. K. (2005). The working poor: Invisible in America. New York: Vintage.

Spriggs, W.E. (2007). The changing face of poverty in America: Why are so many women, children, and racial and cultural minorities still poor? The American Prospect, 18, A5-A7.

Tabachnick, B., \& Fidell, L. (2007). Using multivariate statistics $\left(5^{\text {th }}\right.$ ed.). New York: Pearson Education.

Toomey, T.C., Seville, J.L., Mann, J.D., Abashian, S. W., \& Wingfield, M.S. (1995). Relationship of learned resourcefulness to measures of pain description, psychopathology and health behavior in a sample of chronic pain patients. Clinical Journal of Pain, 11, 259-266.

Turkel, Y.D., \& Tezer, E. (2008). Parenting styles and learned resourcefulness of Turkish adolescents. Adolescence, 43, 143-152.

U.S. Census Bureau. (2006). Income, poverty, and health insurance coverage in the United States: 2006. Washington, DC: Author.

U.S. Census Bureau. (2008). 2006-2008 American Community Survey. Retrieved January 4, 2009 from http://factfinder.census.gov/servlet/ACSSAFFFacts?

U.S. Census Bureau. (2009). Income, poverty, and health insurance coverage in the United States:2008. Washington, DC: Author.

U.S. Department of Health and Human Services. (2008). The 2008 H.H.S. poverty guidelines. Retrieved July 8, 2008 from http://aspe.hhs.gov/poverty/08poverty.shtml

U.S. Department of Labor (2007). A profile of the working poor, 2005. Washington, DC: U.S. Bureau of Labor Statistics.

Weinick, R., Byron, S., \& Bierman, A. (2005). Who can't pay for health care? Journal of General Internal Medicine, 20, 504-509.

West Virginia Department of Health and Human Resources (2007). West Virginia behavioral risk factor survey report 2004-2005. Retrieved July 30, 2008 from:

http://www.wvdhhr.org/bph/oehp/hsc/pubs/BRFSS2004and2005/default.ht $\underline{\mathrm{m}}$ 
West Virginia Department of Health and Human Resources (2009). West Virginia behavioral risk factor survey report 2006. Retrieved March 20, 2009 from:

http://www.wvdhhr.org/bph/oehp/hsc/pubs/BRFSS2006/default.htm

Zagorsky, J. (1999). Health and the working poor. Eastern Economic Journal, 25, 169-189.

Zauszniewski, J.A. (1994a). Health-seeking resources and adaptive functioning in depressed and nondepressed adults. Archives of Psychiatric Nursing, 8, 159-168.

Zauszniewski, J.A. (1994b). Potential sequelae of family history of depression. Identifying family members at risk. Journal of Psychosocial Nursing, 32, 15-21.

Zauszniewski, J.A. (1995a). Learned resourcefulness: A concept analysis. Issues in Mental Health Nursing, 16, 13-31.

Zauszniewski, J.A. (1995b). Health-seeking resources in depressed outpatients. Archives of Psychiatric Nursing, 9, 179-187.

Zauszniewski, J.A. (1996). Self-help and help-seeking behavior patterns in healthy elders. Journal of Holistic Nursing, 14, 223-236.

Zauszniewski, J.A. (1997a). Teaching resourcefulness skills to older adults. Journal of Gerontological Nursing, 23, 14-20.

Zauszniewski, J.A. (1997b). Evaluation of a measure of learned resourcefulness for elders. Journal of Nursing Measurement, 5, 71-86.

Zauszniewski, J.A., \& Chung, C. (2001). Resourcefulness and health practices of diabetic women. Research in Nursing and Health, 24, 113-121.

Zauszniewski, J.A., Chung, C., Chang, H.J., \& Krafcik, K. (2002). Predictors of resourcefulness in school-age children. Issues in Mental Health Nursing, 23, 385-401.

Zauszniewski, J.A., Chung, C., \& Krafcik, K. (2001). Social cognitive factors predicting the health of elders. Western Journal of Nursing Research, 23, 490-503.

Zauszniewski, J.A., Eggenschwiler, K., Preechawong, S., Roberts, B.L., \& Morris, D. L. (2006). Effects of teaching resourcefulness skills to elders. Aging and Mental Health, 10, 404-412. 
Zauszniewski, J.A., \& Martin, M.H. (1999). Developmental task achievement and learned resourcefulness in healthy older adults. Archives of Psychiatric Nursing, 13, 41-47.

Zauszniewski, J.A., McDonald, P.E., Krafcik, K., \& Chung, C. (2002). Acceptance, cognitions, and resourcefulness in women with diabetes. Western Journal of Nursing Research, 24, 728-750.

Zauszniewski, J.A., \& Wykle, M. (1994). Racial differences in self-assessed health problems, depressive cognitions, and learned resourcefulness. Journal of National Black Nurses' Association, 7, 3-14. 
Appendices 


\section{Appendix A: SELF-CONTROL SCHEDULE}

This questionnaire is designed to find out how different people view their thinking and their behavior. A statement may range from very characteristic of you to very uncharacteristic of you.

There are no right or wrong answers. We simply want to know how you feel each statement applies to you.

Please answer every item, and circle only one answer for each item. Use the following code to indicate whether a statement describes your thinking or behavior:

-3 very uncharacteristic of me, extremely undescriptive

-2 rather uncharacteristic of me, quite undescriptive

-1 somewhat uncharacteristic of me, slightly undescriptive

+1 somewhat characteristic of me, slightly descriptive

+2 rather characteristic of me, quite descriptive

+3 very characteristic of me, extremely descriptive 


\begin{tabular}{|c|c|c|c|c|c|c|}
\hline \multirow{2}{*}{$\begin{array}{l}\text { When I do a boring job, I think about the less-boring } \\
\text { parts of the job and about the reward I will receive } \\
\text { when I finish }\end{array}$} & -3 & -2 & -1 & +1 & +2 & +3 \\
\hline & & & & & & \\
\hline \multicolumn{7}{|l|}{$\begin{array}{l}\text { When I have to do something that makes me } \\
\text { anxious, I try to visualize how I will overcome my } \\
\text { anxiety while doing it }\end{array}$} \\
\hline \multicolumn{7}{|l|}{$\begin{array}{l}\text { By changing my way of thinking, I am often able to } \\
\text { change my feelings about almost anything }\end{array}$} \\
\hline \multicolumn{7}{|l|}{$\begin{array}{l}\text { I often find it difficult to overcome my feelings of } \\
\text { nervousness and tension without outside help }\end{array}$} \\
\hline \multicolumn{7}{|l|}{$\begin{array}{l}\text { When I am feeling depressed, I try to think about } \\
\text { pleasant events }\end{array}$} \\
\hline \multicolumn{7}{|l|}{ I cannot help thinking about mistakes I made } \\
\hline \multicolumn{7}{|l|}{$\begin{array}{l}\text { When I am faced with a difficult problem, I try to } \\
\text { approach it in a systematic way }\end{array}$} \\
\hline \multicolumn{7}{|l|}{$\begin{array}{l}\text { I usually do what I'm supposed to do more quickly } \\
\text { when someone is pressuring me }\end{array}$} \\
\hline \multicolumn{7}{|l|}{$\begin{array}{l}\text { When I am faced with a difficult decision, I prefer to } \\
\text { postpone it even if I have all the facts }\end{array}$} \\
\hline \multicolumn{7}{|l|}{$\begin{array}{l}\text { When I have difficulty concentrating on my reading, I } \\
\text { look for ways to increase my concentration }\end{array}$} \\
\hline \multicolumn{7}{|l|}{$\begin{array}{l}\text { When I plan to work, I remove everything that is not } \\
\text { relevant to my work }\end{array}$} \\
\hline \multicolumn{7}{|l|}{$\begin{array}{l}\text { When I try to get rid of a bad habit, I first try to find } \\
\text { out all the reasons why I have the habit }\end{array}$} \\
\hline \multicolumn{7}{|l|}{$\begin{array}{l}\text { When an unpleasant thought is bothering me, I try to } \\
\text { think about something pleasant }\end{array}$} \\
\hline \multicolumn{7}{|l|}{$\begin{array}{l}\text { If I smoked two packs of cigarettes a day, I would } \\
\text { need outside help to stop smoking }\end{array}$} \\
\hline \multicolumn{7}{|l|}{$\begin{array}{l}\text { When I feel down, I try to act cheerful so that my } \\
\text { mood will change }\end{array}$} \\
\hline \multicolumn{7}{|l|}{$\begin{array}{l}\text { If I carried the pills with me, I would take a } \\
\text { tranquilizer whenever I felt tense and nervous }\end{array}$} \\
\hline \multicolumn{7}{|l|}{$\begin{array}{l}\text { When I am depressed, I try to keep myself busy with } \\
\text { things I like }\end{array}$} \\
\hline \multicolumn{7}{|l|}{$\begin{array}{l}\text { I tend to postpone unpleasant tasks even if I could } \\
\text { perform them immediately }\end{array}$} \\
\hline \multicolumn{7}{|l|}{$\begin{array}{l}\text { I need outside help to get rid of some of my bad } \\
\text { habits }\end{array}$} \\
\hline \multicolumn{7}{|l|}{$\begin{array}{l}\text { When I find it difficult to settle down and do a task, I } \\
\text { look for ways to help me settle down }\end{array}$} \\
\hline $\begin{array}{l}\text { Although it makes me feel bad, I cannot help } \\
\text { thinking about all sorts of possible catastrophes }\end{array}$ & & & & & & \\
\hline
\end{tabular}




\begin{tabular}{|c|c|c|c|c|c|c|}
\hline \multirow{2}{*}{$\begin{array}{l}\text { I prefer to finish a job that I have to do before I start } \\
\text { doing things I really like }\end{array}$} & -3 & -2 & -1 & +1 & +2 & +3 \\
\hline & & & & & & \\
\hline \multicolumn{7}{|l|}{ When I feel physical pain, I try not to think about it } \\
\hline \multicolumn{7}{|l|}{$\begin{array}{l}\text { My self-esteem increases when I am able to } \\
\text { overcome a bad habit }\end{array}$} \\
\hline \multicolumn{7}{|l|}{$\begin{array}{l}\text { To overcome bad feelings that accompany failure, I } \\
\text { often tell myself that it is not catastrophic and I can } \\
\text { do something about it }\end{array}$} \\
\hline \multicolumn{7}{|l|}{$\begin{array}{l}\text { When I feel that I am too impulsive, I tell myself to } \\
\text { stop and think before I do anything }\end{array}$} \\
\hline \multicolumn{7}{|l|}{$\begin{array}{l}\text { Even when I feel that I am terribly angry at } \\
\text { someone, I consider my actions very carefully }\end{array}$} \\
\hline \multicolumn{7}{|l|}{$\begin{array}{l}\text { Facing the need to make a decision, I usually find } \\
\text { out all the alternatives instead of deciding quickly } \\
\text { and spontaneously }\end{array}$} \\
\hline \multicolumn{7}{|l|}{$\begin{array}{l}\text { Usually, I first do the things I really like to do even if } \\
\text { there are more urgent things to do }\end{array}$} \\
\hline \multicolumn{7}{|l|}{$\begin{array}{l}\text { When I realize I am going to be unavoidably late for } \\
\text { an important meeting, I tell myself to keep calm }\end{array}$} \\
\hline \multicolumn{7}{|l|}{$\begin{array}{l}\text { When I feel pain in my body, I try to divert my } \\
\text { thoughts from it }\end{array}$} \\
\hline \multicolumn{7}{|l|}{$\begin{array}{l}\text { When I am faced with a number of things to do, I } \\
\text { usually plan my work }\end{array}$} \\
\hline \multicolumn{7}{|l|}{$\begin{array}{l}\text { When I am short of money, I decide to record all my } \\
\text { expenses in order to budget more carefully in the } \\
\text { future }\end{array}$} \\
\hline \multicolumn{7}{|l|}{$\begin{array}{l}\text { If I find it difficult to concentrate on a task, I divide it } \\
\text { into smaller segments }\end{array}$} \\
\hline \multicolumn{7}{|l|}{$\begin{array}{l}\text { Quite often, I cannot overcome unpleasant thoughts } \\
\text { that bother me }\end{array}$} \\
\hline $\begin{array}{l}\text { When I am hungry and have no opportunity to eat, I } \\
\text { try to divert my thoughts from my stomach or try to } \\
\text { imagine I am satisfied }\end{array}$ & & & & & & \\
\hline
\end{tabular}




\section{Scoring Instructions:}

1. Reverse the scoring of the following eleven items:
a. 3
b. 6
c. 8
d. 9
e. 14
f. 16
g. 18
h. 19
i. 21
j. 29
k. 35

For example: if a subject scored item 4 a -3 the reverse score would be +3

2. Sum up all the scores of the individual items. The total score of the scale could range from $-108(36 x-3)$ to $+108(36 x+3)$. For normal populations the score is usually +25 with a standard deviation of 20 


\section{Appendix B: INDEX OF WELL-BEING}

Directions: Here are some words and phrases which I would like you to use to describe how you feel about your present life. Put an $X$ over the line that you think best describes how you feel about your present life.

1. My present life is:

Boring

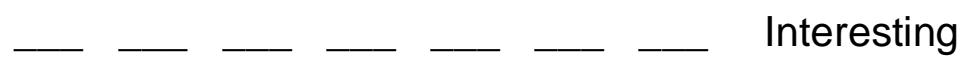

2. My present life is:

Enjoyable

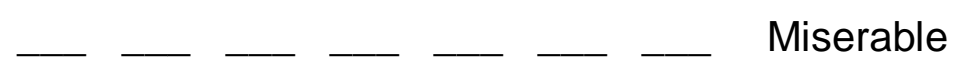

3. My present life is:

Useless

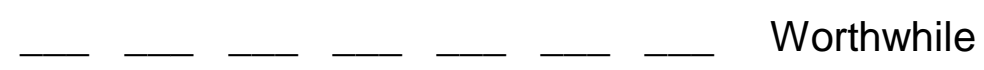

4. My present life is:

Lonely

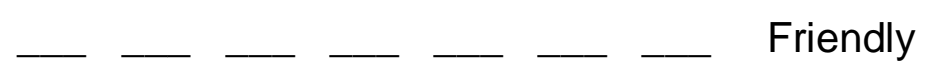

5. My present life is:

Full

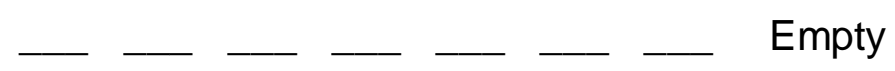

6. My present life is:

Discouraging

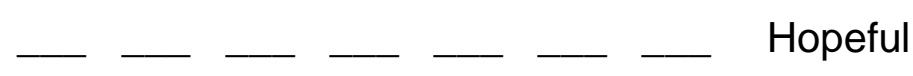

7. My present life is:

Rewarding

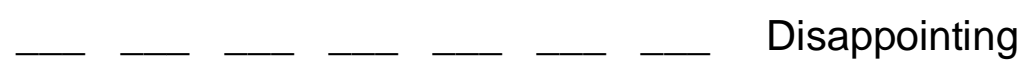

8. My present life:

Doesn't give me

Brings out the

much chance

best in me

9. In thinking about my life as a whole, I am:

Completely

Completely

Dissatisfied

satisfied 


\section{Appendix C: SELECT BEHAVIORAL RISK FACTOR SURVEY ITEMS}

Directions: Choose the answer to the below question which best reflects how you feel or think.

1. Has there been a time in the last year that you have needed medical care but could not afford it?

Yes No

2. Do you have a person you think of as a personal doctor or health care provider?

Yes No

3. Would you say that in general your health is:

Excellent

Very good

Good

Fair

Poor

4. Have you ever been told by a doctor, nurse, or other health provider that you have high blood pressure?

Yes No

5. Have you ever been told by a doctor, nurse, or other health provider that you have diabetes?

Yes No

6. Do you smoke?

Yes No

7. Have you had a PAP test in the past three years?

Yes No

8. In general, how satisfied are you with your life?
Very satisfied
Dissatisfied
Satisfied
Very Dissatisfied 


\section{Appendix D: DEMOGRAPHIC QUESTIONS}

Directions: Please answer the questions below that tell some general information about you.

1. How old are you?

2. How many jobs do you have?

a. Full time

b. Part time

3. Sex:

Female

4. What is your ethnic background?
a. White
b. African American
c. Asian
d. Hispanic
e. Native American
f. Other:

5. What is your marital status?
a. Single
b. Married
c. Divorced
d. Separated
e. Widowed
f. Significant other

6. How far were you able to go in school?
a. Completed middle school
b. Some high school
c. Graduated high school
d. GED
e. Some college/technical school
f. Completed college / technical school
g. Some graduate school
h. Completed graduate school

7. How many people live with you (children, spouse, family members, others)? 
8. Where do you currently live?
a. Homeless - live on the street
b. Homeless - live in a shelter
c. Homeless - live with family or friend
d. Rent
e. Own home
f. Doubled up with a family or friend

9. Have you ever held health insurance?
a. Yes
b. No

If yes to health insurance, how many years since you were last covered? years 


\section{Appendix E: WHEELING HEALTH RIGHT PERMISSION LETTER}

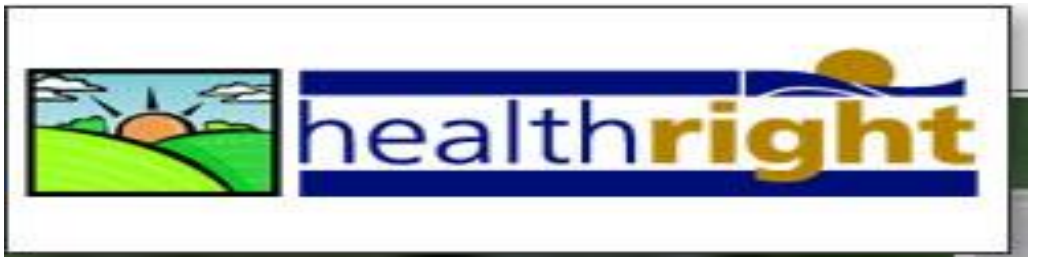

July 7, 2009

West Virginia University

Institutional Review Board

Please let this serve as notice that Wheeling Health Right recognizes and welcomes Denise Lucas, RN, MSN, CRNP, Doctoral Candidate as she uses the Wheeling Health Right Clinic as the location for her research study while completing degree requirements at West Virginia University. I recognize the study will involve patients at our center and that the patients will be asked to complete surveys as part of the research study.

Wheeling Health Right does not have an Institutional Review Board (IRB) and West Virginia University will serve as the IRB of record.

Sincerely,

Kathie H. Brown

Executive Director

Wheeling Health Right

$8814^{\text {th }}$ Street, Wheeling, WV 26003

304-233-3869 


\section{Do you have a few minutes for a research study?}

Do you have 10-15 minutes to fill out a few surveys forms? There is a student doing a research study looking for input from women receiving care at Health Right.

Your answers will give information about women without insurance who are receiving health care.....how they learn to be resourceful, how they view their well-being, and how they manage their health.

The student conducting the study is Denise Lucas. She is a nurse, a family nurse practitioner, and a doctoral student at West Virginia University.

To participate in the study you must be:

- Female

- Between the ages of 25 - 65 years old

- A patient at Wheeling Health Right

If interested see Denise Lucas in the lobby for a survey packet. Your input will be very valuable.

All information is confidential and will be reviewed by the researcher only. Participation is voluntary and will have no effect on your care at Health Right. 
Appendix G: PARTICIPANT

LETTER

\section{West Virginia University}

SCHOOL OF NURSING

\section{Dear Health Right Patient,}

My name is Denise Lucas and I am a nurse and a doctoral student at West Virginia University. I am doing a study that looks at some health measures in women who are receiving care at a free clinic. The study is supervised by Dr. Mary Jane Smith, a professor in the School of Nursing at the University. The time you take to fill out the survey forms will be greatly appreciated. Please consider giving your input and answering the survey forms, which is estimated to take about 10-15 minutes

Some things to know about the study:

- Your participation is voluntary

- This study asks for women age $25-65$ years old

- Whether you participate or not will have no affect on your care at Wheeling Health Right

- Your answers to the surveys will not be shared with the Health Right Staff

- I am not asking any information that can identify you or be traced back to you

- There are no known risks or discomforts associated with the study

- The study packet contains four brief surveys

- You may skip any question(s) you do not wish to answer and stop the survey any time if you decide you do not want to participate

- The West Virginia University Institutional Review Board acknowledgement of this project is on file

I sincerely hope you will take a few minutes and participate in this project. The information you provide can help nurses to understand some behaviors in women such as how they learn to be resourceful, how they view their well-being, and how they manage some parts of their health.

Thank you very much for your time. If you have any questions about this letter or the research project please call me (Denise Lucas) at 304-797-7254 or email at dlucas7@mix.wvu.edu. You may also phone Dr. Mary Jane Smith at 304-293-4296. For information about your rights as a research participant you may contact the Office of Research Compliance at West Virginia University at 304-293-7073. 